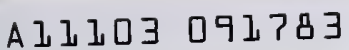

NBS Special Publication 480-28

NBS

Publi cations
The Development and Testing of a Highly Directional Dual-Mode Electronic Siren

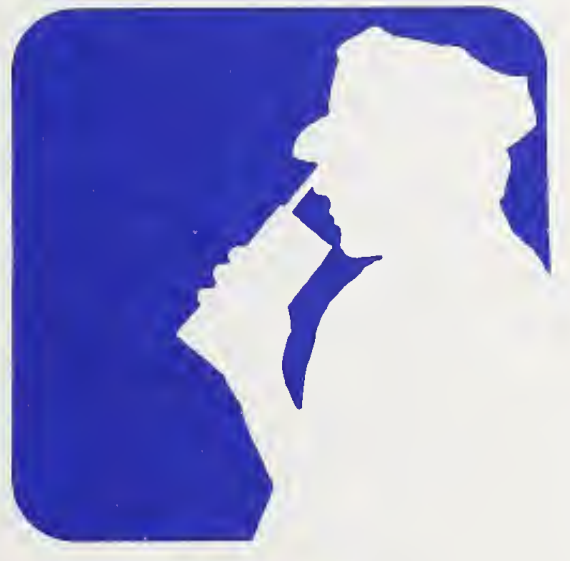

Law Enforcement Equipment Technology

U.S. DEPARTMENT OF COMMERCE

National Bureau of

Standards

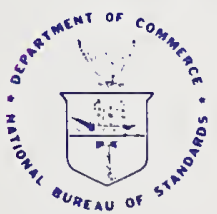



NBS Special Publication $480-28$

vest occ-Ref

at Bureav of Stamerese

241978

\section{The Development and Testing of a Highly Directional Dual-Mode Electronic Siren}

prepared by
R. L. Fisher, D. D. Toth, D. S. Blomquist,
J. S. Forrer
Acoustics and Noise Program
National Bureau of Standards
and the
Law Enforcement Standards Laboratory
Center for Consumer Product Technology
National Bureau of Standards
Washington, D. C. 20234

prepared for

National Institute of Law

Enforcement and Criminal Justice

Law Enforcement Assistance Administration

U.S. Department of Justice

Washington, D.C. 20531

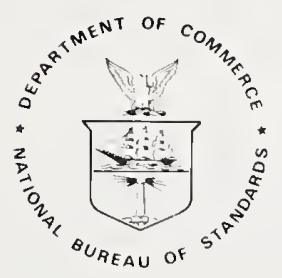

Issued February 1978

U.S. DEPARTMENT OF COMMERCE, Juanita M. Kreps, Secretary Dr. Sidney Harman, Under Secretary Jordan J. Baruch, Assistant Secretary for Science and Technology NATIONAL BUREAU OF STANDARDS, Ernest Ambler, Acting Director 
Library of Congress Cataloging in Publication Data

Main entry under title:

The Development and testing of highly directional dual-mode electronic siren.

(Law enforcement equipment technology) (NBS special publication : 480-28)

Bibliography: p.

Supt. of Docs. no.: C 13.10:480-28

1. Sirens (Signaling devices)-Testing.

1. Fisher, Ronald L. 11. National Institute of Law Enforcement and Criminal Justice 111. Law Enforcement Standards Laboratory. IV. Title. V. Series. V1. Series: United States. National Bureau of Standards. Special publication ; 480-28. QC100.U57 no. 480-28 [TK5990] 602'. Is [621.389'2] 77-17493

\section{National Bureau of Standards} Special Publication 480-28

Nat. Bur. Stand. (U.S.), Spec. Publ. 480-28, 51 pages CODEN XNBSAV

\section{U.S. GOVERNMENT PRINTING OFFICE WASHINGTON: 1978}

For sale by the Superintendent of Documents, U.S. Government Printing Office, Washington, D.C. 20402 (Order by SD Catalog No. C13.10:480-28). Stock No. 003-003-01925.9 (Add 25 percent additional for other than U.S. mailing). 


\section{FOREWORD}

The Law Enforcement Standards Laboratory (LESL) of the National Bureau of Standards (NBS) furnishes technical support to the National Institute of Law Enforcement and Criminal Justice (NILECJ) program to strengthen law enforcement and criminal justice in the United States. LESL's function is to conduct research that will assist law enforcement and criminal justice agencies in the selection and procurement of quality equipment.

LESL is: (1) Subjecting existing equipment to laboratory testing and evaluation and (2) conducting research leading to the development of several series of documents, including national voluntary equipment standards, user guidelines, state-of-the-art surveys and other reports.

This document is a law enforcement equipment report developed by LESL under the sponsorship of NILECJ. Additional reports as well as other documents are being issued under the LESL program in the areas of protective equipment, communications equipment, security systems, weapons, emergency equipment, investigative aids, vehicles and clothing.

Technical comments and suggestions concerning the subject matter of this report are invited from all interested parties. Comments should be addressed to the Law Enforcement Standards Laboratory, National Bureau of Standards, Washington, D.C. 20234.

Jacob J. Diamond

Chief, Law Enforcement Standards Laboratory 



\section{CONTENTS}

Foreword

Page

1. Introduction

2. Highly Directional Dual-Mode Siren System Design

2.1 NBS System 1: Swept-Beam Dual-Mode Siren

2.2 NBS System 2: Phased Dual-Mode Siren

3. Full Power Tests in Anechoic Room

3.1 Testing Commercial Electronic Siren in Anechoic Room

3.2 Testing NBS System 1 Dual-Mode Siren in Anechoic Room

3.3 Testing NBS System 2 Dual-Mode Siren in Anechoic Room

3.4 Testing the Acoustical Effects of Warning Lights Mounted on Both Ends of Siren Array

3.5 The Effect of Loudspeaker Size on Siren Array Directivity Pattern

4. Low Power Tests of Siren Mounted on a Full Size Sedan

4.1 Attenuation versus Distance from Sirens

4.2 Scaling Low Power Test Results Measured on a Vehicle to the Equivalent Full Power Output Results

4.3 Comparison of the Wail and Yelp Directivity Patterns

5. Conclusions

References

Glossary

Appendix A-Description of NBS System 1 Dual-Mode Directional Siren

Appendix B-Reasons for Choosing a Broadside Array and Design for NBS System 2 Dual-Mode Directional Siren 


\section{LIST OF FIGURES}

Figure 1. Typical horizontal directivity patterns of two array types. (Vehicles are shown by the rectangular outlines.)

Figure 2. Four speaker siren array with $15.2 \mathrm{~cm}(6.0 \mathrm{in})$ center-to-center spacing in anechoic room

Figure 3. Snept beam dual-mode siren (System l)

Figure 4. Electronics modules for NBS System 1 dual-mode siren

Figure

5. Phased dual-mode siren (System 2).

Figure 6. Schematic block diagram of data acquisition and analysis instrumentation for siren measurements in anechoic room

Figure

7. Dual-mode siren array and condenser microphone in anechoic room

Figure 8. Commercial electronic siren used in directivity comparison tests with dual-mode siren

Figure 9. Full power, A-weighted, horizontal directivity pattern for commercial 100 watt electronic siren

Figure 10. Full power, A-weighted, horizontal directivity pattern for NBS System 1 dual-mode siren in forward mode

Figure 11. Full power, A-weighted, horizontal directivity pattern for NBS System 1 dual-mode siren in intersection mode

Figure 12. Full power, A-weighted, horizontal directivity pattern for NBS System 2 dual-mode siren in forward mode

Figure 13. Full power, A-weighted, horizontal directivity pattern for NBS System 2 dual-mode siren in intersection mode

Figure 14. Effect of warning lights on full power, A-weighted, horizontal directivity pattern for NBS System 2 dual-mode siren in forward mode

Figure 15. Effect of warning lights on full power, A-weighted, horizontal directivity pattern for NBS System 2 dual-mode siren in intersection mode

Figure 16. NBS large horn siren array with $15.2 \mathrm{~cm}(6.0 \mathrm{in})$ center-to-center spacing

Figure 17. Effect of horn size on full power, A-weighted, horizontal directivity pattern for NBS System 1 dual-mode siren in forward mode

Figure 18. Effect of horn size on full power, A-weighted, horizontal directivity pattern for NBS System 2 dual-mode siren in forward mode 


\section{LIST OF FIGURES-Continued}

Figure 19. Effect of horn size on full power, A-weighted, horizontal directivity pattern for NBS System 1 dual-mode siren in intersection mode

Figure 20. Effect of horn size on full power, A-weighted, horizontal directivity pattern for NBS System 2 dual-mode siren in intersection mode

Figure 21. Test site for sirens on vehicle

Figure 22. NBS dual-mode siren at outdoor test site

Figure 23. Third-octave band spectrum of background noise and NBS siren signals at outdoor test site

Figure 24. Siren signal attenuation as a function of distance

Figure 25. Free field response of electronic siren speaker to a $1000 \mathrm{~Hz}$ sine wave ....

Figure 26. A-weighted, horizontal directivity pattern scaled to full power for 100 watt commercial electronic siren on vehicle

Figure 27. A-weighted, horizontal directivity pattern scaled to full power for NBS System 1 dual-mode siren on vehicle in forward mode

Figure 28. A-weighted, horizontal directivity pattern scaled to full power for NBS System 1 dual-mode siren on vehicle in intersection mode

Figure 29. A-weighted, horizontal directivity pattern scaled to full power for NBS System 1 dual-mode siren modified to steer to $30^{\circ}$

Figure 30. A-weighted, horizontal directivity pattern scaled to full power for NBS System 1 dual-mode siren modified to steer to $60^{\circ}$

Figure 31. A-weighted, horizontal directivity pattern scaled to full power for NBS System 1 dual-mode siren modified to steer to $90^{\circ}$

Figure 32. A-weighted, horizontal directivity pattern scaled to full power for NBS System 2 dual-mode siren on vehicle in intersection mode

Figure 33. A-weighted, horizontal directivity pattern scaled to full power for NBS System 1 dual-mode siren on vehicle in forward mode, wail signal

Figure 34. A-weighted, horizontal directivity pattern scaled to full power for NBS System 1 dual-mode siren on vehicle in intersection mode, wail signal ....

Figure 35. A-weighted, horizontal directivity pattern scaled to full power for NBS System 2 dual-mode siren on vehicle in intersection mode, wail signal ....

Figure 36. Dual-mode siren array on vehicle

Figure 37. Closeup photograph of dual-mode siren array on vehicle 


\section{LIST OF FIGURES-Continued}

Figure 38. A-weighted, horizontal directivity pattern comparison of NBS System 1 dual-mode siren in forward mode with commercial electronic siren on vehicle

Figure 39. A-weighted, horizontal directivity pattern comparison of NBS System 1 dual-mode siren in intersection mode with commerical electronic siren on vehicle

Figure 40. A-weighted, horizontal directivity pattern comparison of NBS System 2 dual-mode siren in intersection mode with commercial electronic siren on vehicle

Figure A-1. Block diagram of swept-beam dual-mode siren (System 1)

Figure B-1. Theoretical directivity patterns for linear broadside point source arrays ( $25 \mathrm{~dB}$ range)

Figure B-2. Theoretical directivity patterns for linear endfire point source arrays (25 dB range)

Figure B-3. Theoretical directivity patterns for System 2 array (25 dB range)

Figure B-4. Block diagram of phasing network for NBS asymmetrically phased dualmode siren (System 2)

Figure B-5. Measured phase of filter for asymmetric array

Figure B-6. Theoretical directivity patterns for symmetric array (25 dB range)

Figure B-7. A-weighted, full power horizontal directivity pattern for symmetric phased siren array in intersection mode (modified System 2)

Figure B-8. Block diagram of phasing network for NBS symmetrically phased dualmode siren (modified System 2)

Figure C-1. Clock board and delay board for NBS swept-beam siren (System 1) ....

Figure C-2. Program board for NBS swept-beam siren (System 1)

Figure C-3. Filter network for NBS System 2 siren using asymmetric phasing

Figure C-4. Filter network for modified NBS System 2 siren using symmetric phasing.

\section{LIST OF TABLES}

Table 1. Comparison of component parts and capabilities of the NBS dual-mode siren and a conventional electronic siren 


\title{
THE DEVELOPMENT AND TESTING OF A HIGHLY DIRECTIONAL DUAL-MODE ELECTRONIC SIREN
}

\author{
R. L. Fisher, D. D. Toth, D. S. Blomquist, J. S. Forrer \\ Applied Acoustics Section, National Bureau of Standards
}

\begin{abstract}
NBS has developed a dual-mode directional electronic siren which can be electrically switched under manual control from a strong narrow beam of sound in the forward direction for open highway usage to a broader beam for use near roadway intersections. The intense beam of sound is produced by a vehicularroof-mounted broadside array consisting of four compact commercial 100 watt electronic siren loudspeakers spaced $15.2 \mathrm{~cm}$ (6.0 in) apart. Two electronic systems were developed to broaden the inherently narrow beam of the broadside array. One system swept the beam from side to side. The second system involved the use of a filter network. A-weighted sound pressure level measurements made in an anechoic chamber and outdoors on a rehicle showed that the maximum sound pressure level of the NBS dual-mode siren is 7 to $10 \mathrm{~dB}$ higher in the desired directions than a single 100 watt commercial electronic siren.
\end{abstract}

Key words: Acoustics; broadside array; directional siren; dual-mode siren; emergency warning device; loudspeaker array; phased array siren; sound.

\section{INTRODUCTION}

Patrol cars, fire engines, ambulances and other public safety vehicles making emergency runs are known to be involved in automobile accidents with more than average frequencies. These accidents tend to happen at intersections, and are at least partly caused by the occasional failure of their emergency warning devices (sirens and/or flashing lights) to effectively warn cross traffic of their approach.

This research was prompted by that situation. The assigned task was to develop a dualmode emergency vehicle siren, which would operate in one mode on the open highway and in a second mode when approaching an intersection.

In the forward mode, the siren was to project as great a proportion as possible of its sound energy in a relatively narrow beam straight ahead, with a minimum going to the sides as noise pollution. In the intersection mode, the siren was to direct the maximum possible sound diagonally to the front sides, while retaining a reasonable effectiveness straight ahead. The sound pressure levels in both operational modes were to be equal to or greater than those available from commerical sirens, and the transition between the two modes was to be achievable by means of a simple switch at the driver's position. 


\section{HIGHLY DIRECTIONAL DUAL-MODE SIREN SYSTEM DESIGN}

At the start of this project, the authors conducted a literature search on the state of the art of directional sound sources, using the computerized literature search services available at the NBS library.

No existing acoustical system was found that was appropriate for emergency vehicles. For example, vehicular roof mounted parabolic reflectors $[3,5,8]^{1}$ and acoustic lenses [1] were briefly considered as means of focusing sound waves into a directional beam. Their disadvantages were two-fold. First, each device would require a diameter of about 1 meter (3 ft) producing objectionable drag at high vehicular speed. Secondly, widening the beamwidth when approaching roadway intersections would have required mechanical motion of the lens, reflector, or output transducer. A broad band directional sound source could have been designed based on the gradient loudspeaker [7], an acoustic reciprocal of the highly directional gradient microphone [6]. A so-called first-order gradient loudspeaker system consists of two loudspeakers mounted one behind the other with the back of each speaker acoustically sealed in a small enclosure. The signal to the front speaker is time delayed with respect to the signal applied to the rear loud speaker, thus forming an endfire array. The first-order gradient loudspeaker, therefore, is a special case of the arrays discussed below. A second-order gradient loudspeaker, like the first-order, consists of two loudspeakers in an endfire arrangement but with both sides of each moving diaphragm (spéaker cone) exposed. Since most outdoor loud-speakers have fully enclosed transducer elements mated to rugged folded horns, the second-order gradient loudspeaker concept did not appear to be practical for the construction of a siren to be used on an emergency vehicle.

A literature search was then made to determine whether analogous sonar systems or radiofrequency antennas with variable directivity could be used as design concepts for vehicle sirens. Two general classes of line arrays, the "broadside" and "endfire" [2,4], ap. peared to be promising. The two general classes of line arrays, together with possible forward radiation patterns, are shown in figure 1 superimposed on vehicle outlines. The theoretical free-field radiation patterns were plotted on a graphics terminal by a computer program written to simulate arrays of point sources (each having an omnidirectional radiation pattern).

The left half of figure 1 depicts the so-called endfire array, in which a strong beam of sound is produced on axis (to the front of the vehicle) by proportionally time delaying signals to all but the rear source so that the sound waves are in phase as they pass the front point source. The right side of figure 1 presents the broadside array, which produces a narrow beam to the front (and rear) of the vehicle. At first glance the endfire array would seem more appropriate for emergency vehicles because it has a broader beam than the broadside pattern.

In actual practice, however, the theoretical point sources must be approximated by real sources whose length, width and height are not negligible and, in this case, they are about 19 , 13 , and $21 \mathrm{~cm}(7.5,5.1$, and $8.3 \mathrm{in})$, respectively. The endfire array requires a center-tocenter element spacing of about $9 \mathrm{~cm}$ (3.6 in) to obtain broad-beam patterns over the siren signal frequency range of 500 to $1500 \mathrm{~Hz}$. An attempt was made to overcome the problem of narrow spacing between source elements by not using individual loudspeakers. An acoustic linear endfire array was constructed from a $3.5 \mathrm{~cm}(1.4$ in) diameter aluminum pipe $1.3 \mathrm{~m}$ (51 in) long. A 60 watt loudspeaker driver was inserted in one end of the pipe. The other end of the pipe was closed off with a sound absorbing acoustic wedge. Twelve holes were 

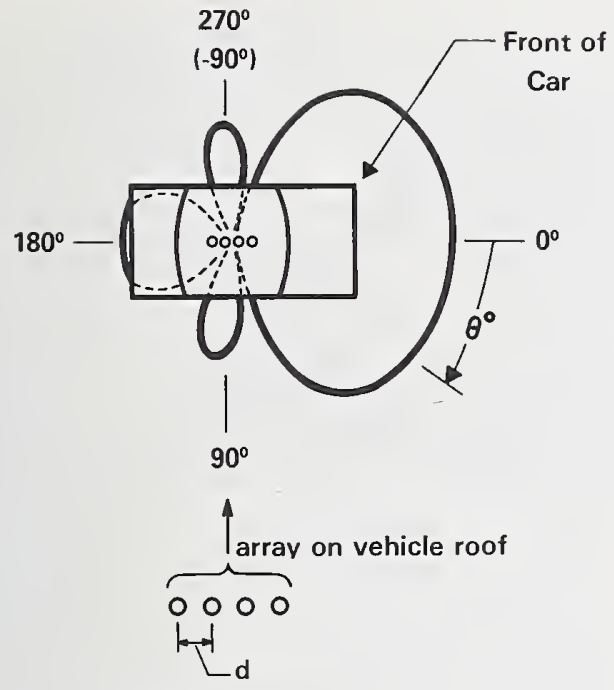

Point Source

Endfire Array

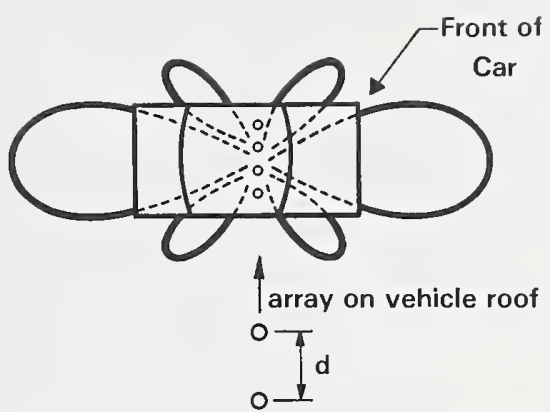

O

0

Point Source

Broadside Array

FIGURE 1. Typical horizontal directivity patterns of two array types.

(Vehicles are shown by the rectangular outlines.)

drilled along the pipe to form the array. Although the array produced a narrow beam of sound. the efficiency of the system was too low to produce the high sound pressure levels needed in a practical siren and, accordingly, this was abandoned.

To help determine the optimum array that would permit a dual mode of operation at high sound pressure levels, the computer program for simulating point source arrays was run to plot theoretical directivity patterns for arrays consisting of two to seven sources with sources spaced 0.1 to 1.0 wavelengths apart. ${ }^{2}$ The results from this simulation showed that a broadside array of four sirens with center-to-center element spacing of $15.2 \mathrm{~cm}(6.0$ in) between siren horns should be able to produce a narrow forward beam of sound and, with no physical movement of the siren horns, could also produce a broad beam by electronically shifting the relative phase between source input signals.

The narrow beam of the broadside array with four sirens is useful for open highway travel because the array produces a sound pressure level which is, in theory, $12 \mathrm{~dB}$ higher toward the front of the emergency vehicle than that from a single siren. A center-to-center spacing of $15.2 \mathrm{~cm}$ (6.0 in) allows construction of the broadside array with efficient high power speakers. This speaker array is shown in the NBS anechoic room in figure 2.

Two separate electronic systems (System 1 and System 2) were developed to broaden the inherently narrow beamwidth of the broadside array. Both systems allow the narrow beamwidth (open highway usage) to be changed to a wider beamwidth for use near roadway intersections by manually operating a toggle switch on the siren control module. 


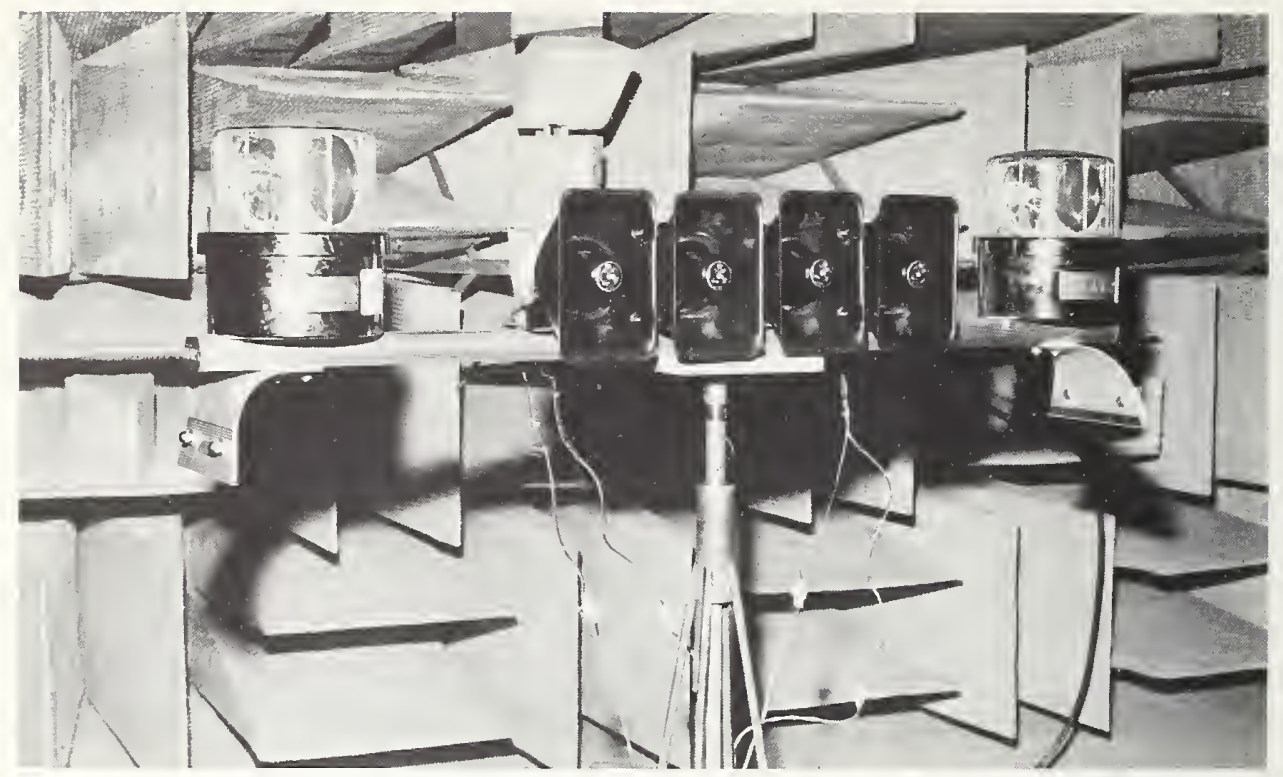

Figure 2. Four speaker siren array with $15.2 \mathrm{~cm}(6.0$ in) center-to-center spacing in anechoic room.

\subsection{NBS System 1: Swept-Beam Dual-Mode Siren}

System 1, as shown in figures 3 and 4 , consisted of a commercial siren control module, a specially designed time delay network, four commercial power amplifiers, and four commercial high power speakers arranged in a broadside array. Utilizing an integrated circuit delay device, the beam was linearly swept in 256 steps (about $1.4^{\circ} /$ step) from $-90^{\circ}$ to $+90^{\circ}$ to $-90^{\circ}$ with respect to the front of the vehicle. The time for one complete sweep could be adjusted from less than 1 second to more than 15 seconds by rotating a control knob on the time delay device.

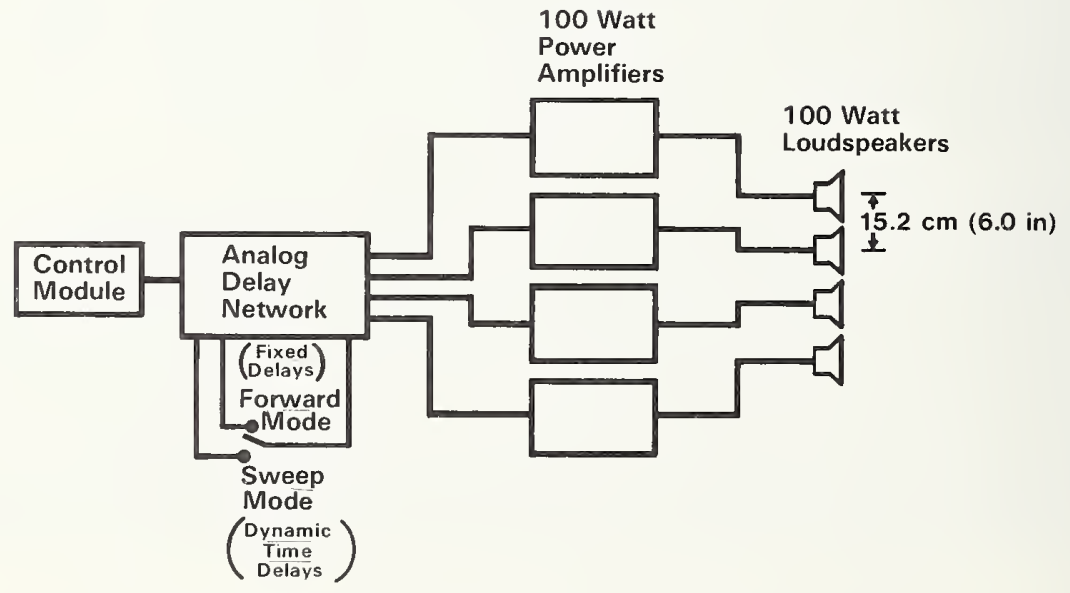

Figure 3. Suept beam dual-mode siren (System 1). 


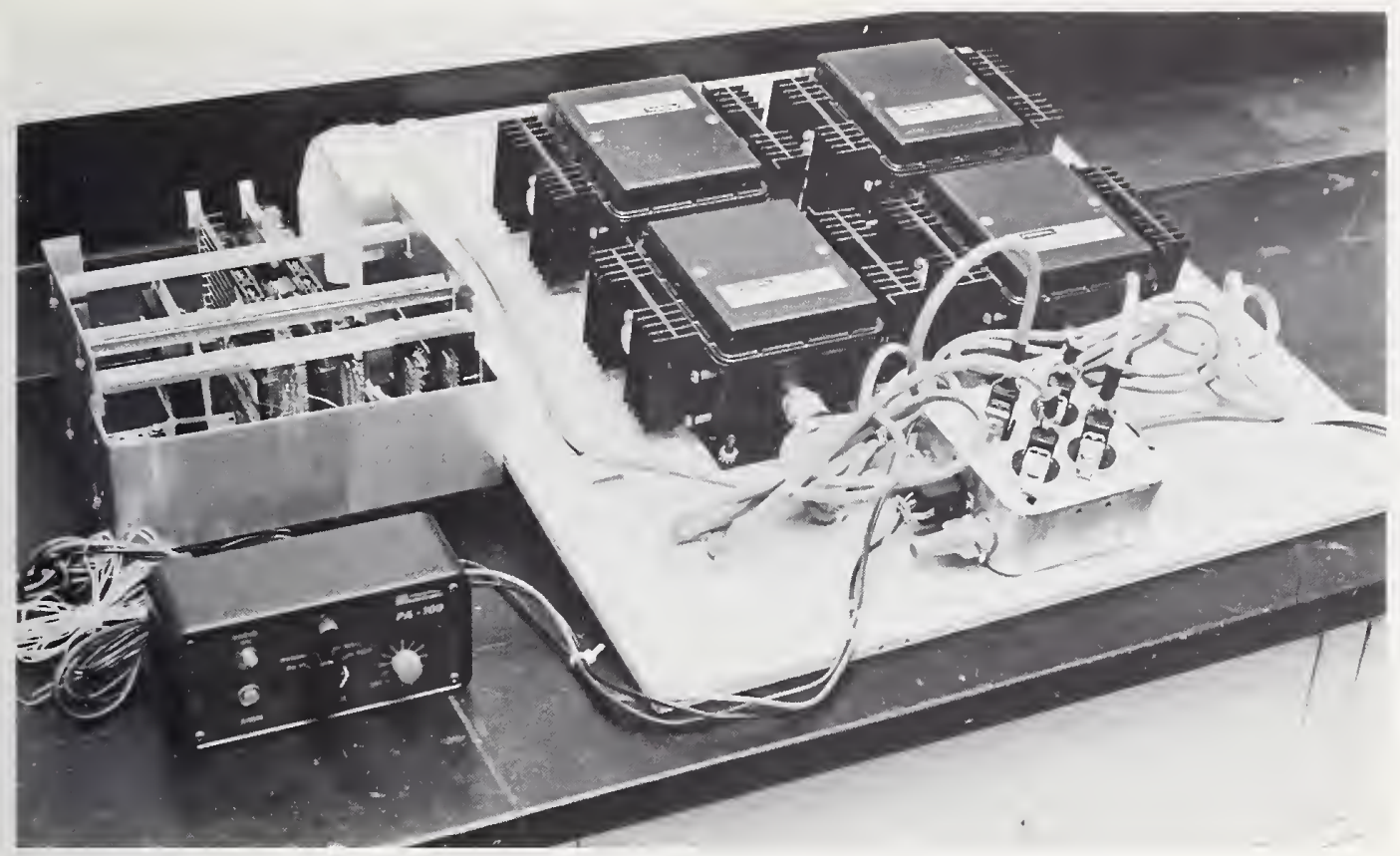

Figure 4. Electronics modules for NBS System 1 dual-mode siren.

\subsection{NBS System 2: Phased Dual-Mode Siren}

The second method developed to broaden the beamwidth consisted of the same equipment as used in System 1 except for the phasing network and the use of only two power amplifiers. The block diagram of System 2 is shown in figure 5. One power amplifier received its signal directly from the siren control module and drove two of the four speakers wired in parallel. The second power amplifier, connected to the remaining two speakers, received the siren signal after the signal passed through an active filter network. The frequency-dependent phase characteristics of the filter network effectively transformed the array into an endfire array at selected frequencies, thus directing the sound beam to the sides of the vehicle.

These two systems are more fully discussed in appendices $\mathrm{A}$ and $\mathrm{B}$.

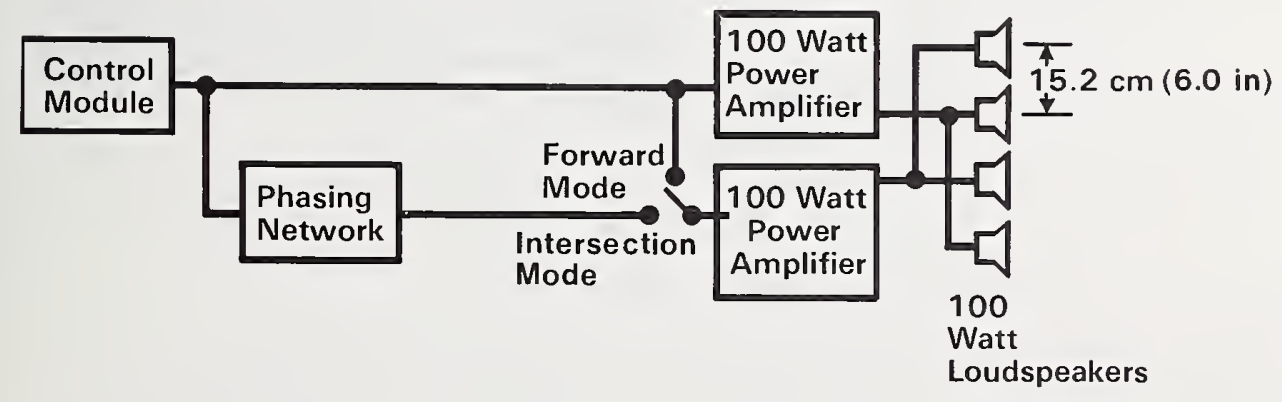

Figure 5. Phased dual-mode siren (System 2). 


\section{FULL POWER TESTS IN ANECHOIC ROOM}

Full power tests on a commercial electronic siren and the two versions of the NBS dual-mode siren were made in the NBS anechoic room to provide data for full power directivity patterns. The measuring equipment consisted of a microphone, preamplifier. main amplifier, 1/3-octave band real time analyzer, and a minicomputer system with a digital magnetic tape unit for storing directivity pattern data. A block diagram showing the measuring equipment is depicted in figure 6 . The siren was mounted on a turntable which was rotated in $10^{\circ}$ increments between data points. A one-half-inch microphone was fixed at three meters $(9.8 \mathrm{ft})$ from the siren and was at the same height as the siren (see fig. 7). The minicomputer was programmed to have the real time analyzer sample the test signal every 0.1 second during a total of 20 seconds at each test position to enable averaging the time-varying yelp siren signal. For wail signals and for the sweep mode of System 1, the signal was sampled every 0.3 second during a total of 60 seconds at each test position so that many complete cycles of the signal would be averaged. The reported A. weighted sound pressure levels were averaged over time on an energy basis. The average A-weighted level at each position along with the instantaneous A-weighted, flat, and 1/3octave band data were stored on digital magnetic tape. A 13.5 volt direct-current power supply was used to drive the siren equipment.

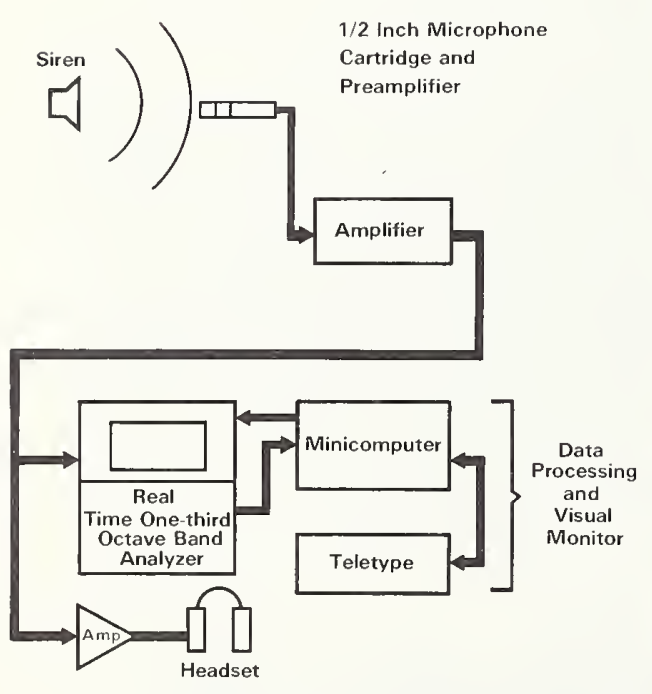

Figure 6. Schematic block diagram of data ac. quisition and analysis instrumentation for siren measurements in anechoic room.

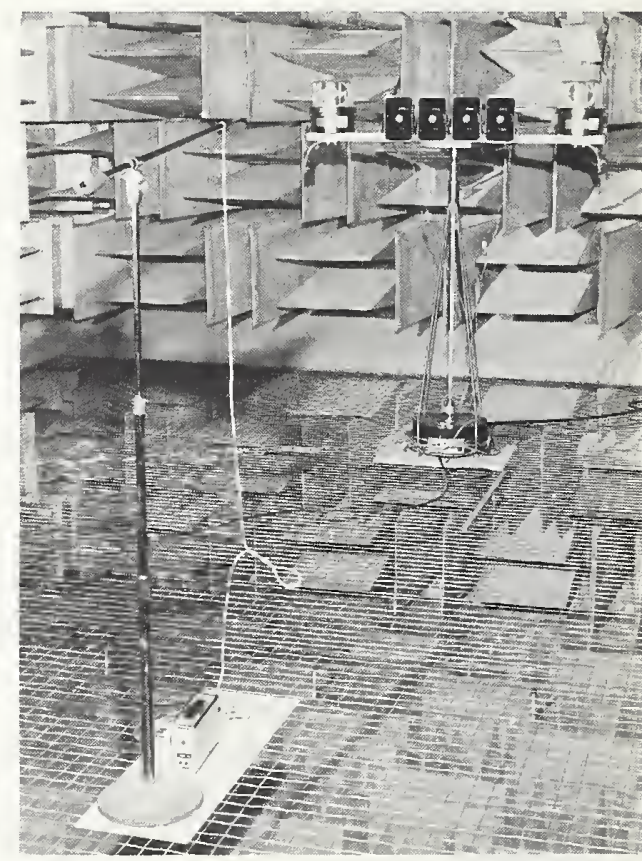

Figlre 7. Dual-mode siren array and condenser microphone in anechoic room.

\subsection{Testing Commercial Electrionic Siren in Anechoic Room}

A completely commercial siren system (fig. 8), consisting of a control module, a 100 watt power amplifier, and a 100-watt loudspeaker, was tested for comparison purposes; the free-field directivity pattern for the yelp-mode signal is shown in figure 9. The average 


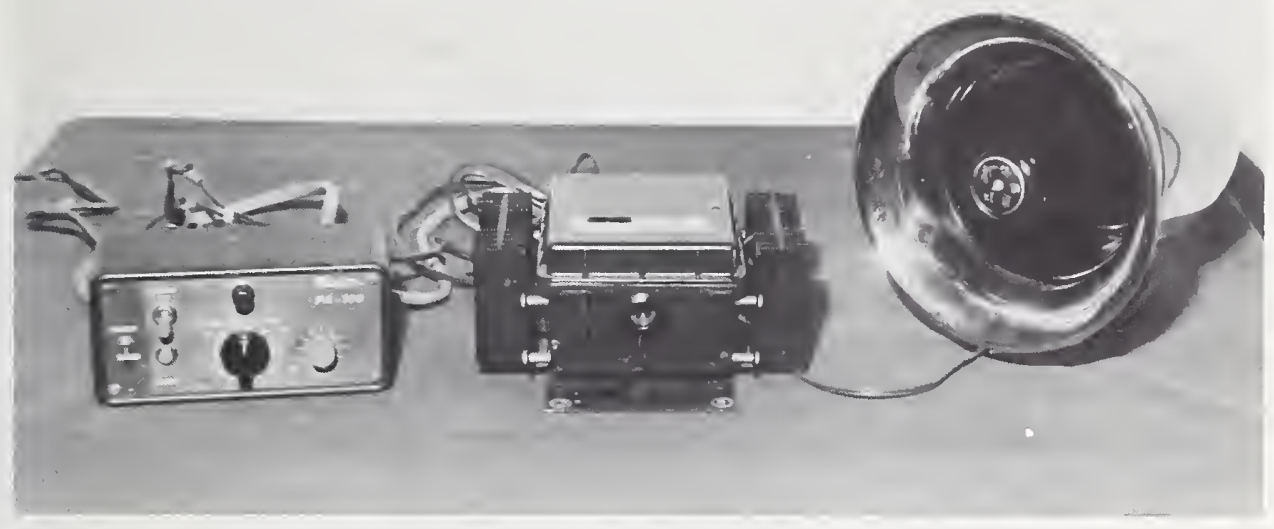

Figure 8. Commercial electronic siren used in directivity comparison tests with dual-mode siren.

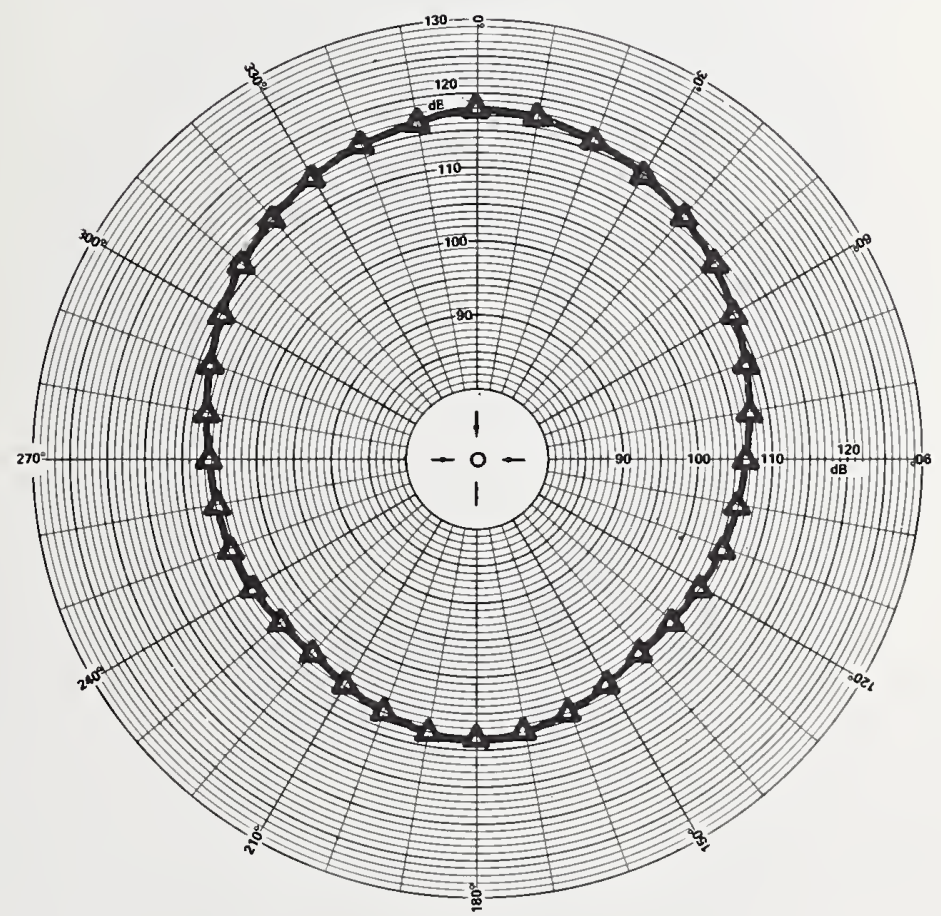

FIGURE 9. Full power, A-ueighted, horizontal directivity pattern for commercial 100 watt electronic siren.

Test conditions: free field, $3 \mathrm{~m}(9.8 \mathrm{ft})$ measurement distance, yelp signal 
A-weighted level on axis (straight ahead) at 3 meters $(9.8 \mathrm{ft}$ ) distance was $118 \mathrm{~dB}$. The level smoothly dropped to $107 \mathrm{~dB}$ at $\pm 90^{\circ}$ (to the side). At $\pm 50^{\circ}$, which we have arbitrarily selected (for discussion purposes) as the angle of interest when approaching an intersection, the sound pressure level was $112 \mathrm{db}$.

\subsection{Testing NBS System 1 Dual-Mode Siren in Anechoic Room}

The NBS System 1 dual-mode siren was operated at full power in the anechoic chamber using the yelp signal. The directivity pattern produced at 3 meters $(9.8 \mathrm{ft})$ in the forward or open-highway mode is shown in figure 10. An average A-weighted level of $128 \mathrm{~dB}$ was recorded on axis (to the front); this was $10 \mathrm{~dB}$ higher than that of the conventional electronic siren. The average levels at $\pm 50^{\circ}$ and $\pm 90^{\circ}$ were $109 \mathrm{~dB}$ and $107 \mathrm{~dB}$, respectively; these were equal to or less than those of the conventional siren, and are a measure of the relative noise pollution of the two sirens.

Assuming spherical spreading (i.e., the sound pressure level drops $6 \mathrm{~dB}$ per doubling of distance), the $10 \mathrm{~dB}$ increase in level in the forward direction implies that the NBS siren (System 1) in the forward mode should be detectable at three times the range of a conventional siren.

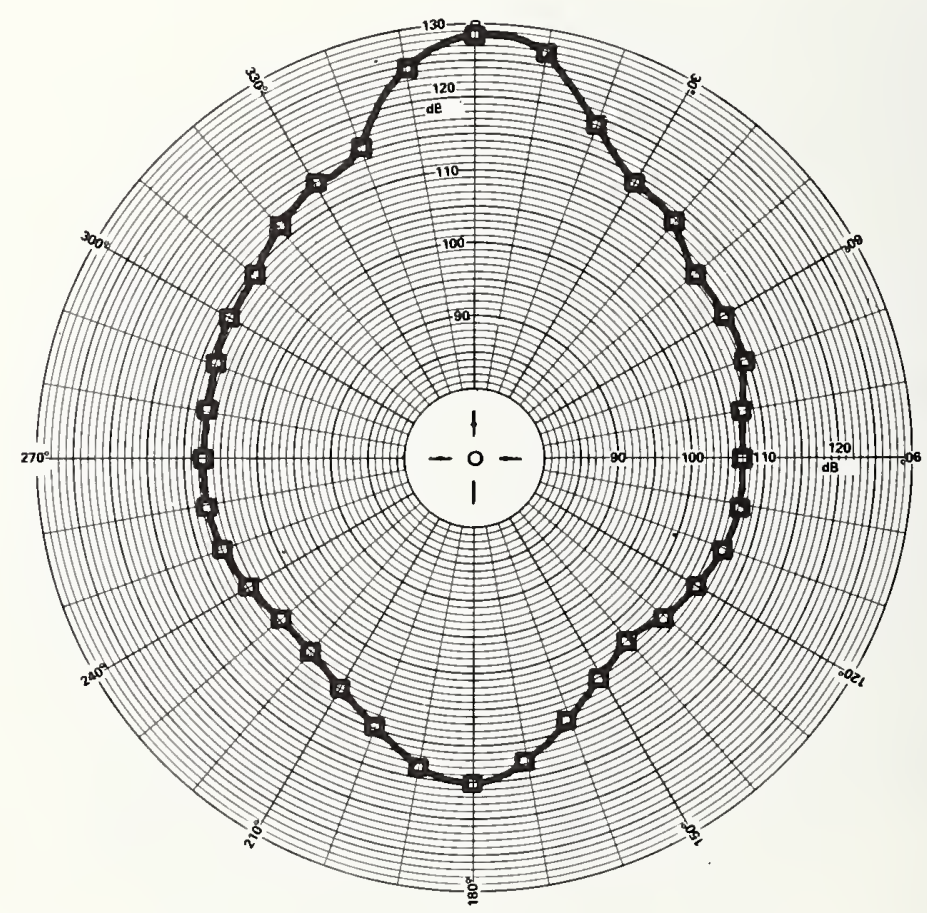

Figure 10. Full-poter, A-weighted, horizontal directivity pattern for NBS System $l$ dual-mode siren in forward mode.

Test conditions: free field, $3 \mathrm{~m}(9.8 \mathrm{ft})$ measurement distance, yelp signal 
The directivity pattern produced at 3 meters $(9.8 \mathrm{ft})$ in the sweep mode, as temporally averaged over several entire angular sweeps, is given in figure 11. The on-axis A-weighted sound level was $121 \mathrm{~dB}, 3 \mathrm{~dB}$ more than the conventional siren, and the sound level at $\pm 50^{\circ}$ was $120 \mathrm{~dB}$. The increase of $10 \mathrm{~dB}$ for the NBS System 1 siren over the conventional electronic siren at $\pm 50^{\circ}$ implies that, in the intersection mode too, it should be detectable three times as far away.

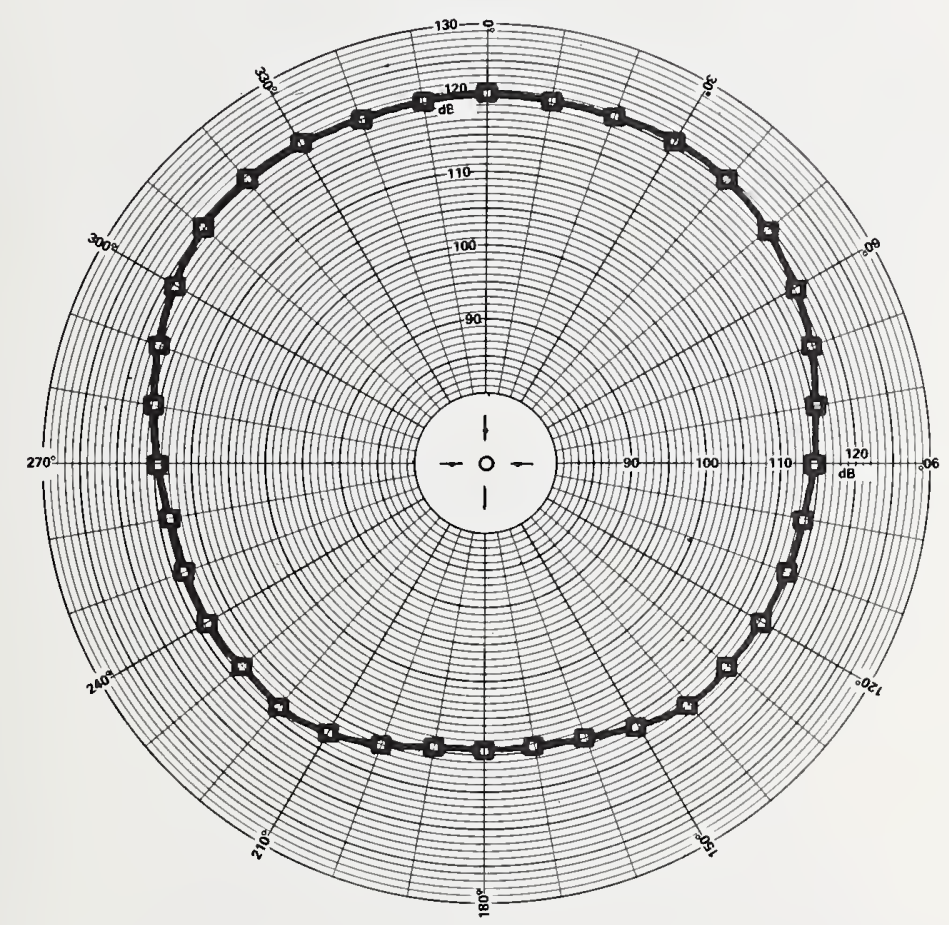

Figure 11. Full power, A-weighted, horizontal directivity pattern for NBS System I dual-mode siren in intersection mode.

Test conditions: free field. $3 \mathrm{~m}(9.8 \mathrm{ft})$ measurement distance. yelp signal

\subsection{Testing NBS System 2 Dual-Mode Siren in Anechoic Room}

The NBS System 2 dual-mode siren was operated at full power in the anechoic chamber using the yelp signal. The directivity pattern produced at 3 meters $(9.8 \mathrm{ft})$ in the forward mode is shown in figure 12. An average A-weighted sound pressure level response of 128 $\mathrm{dB}$ was recorded on axis (to the front). The average levels at $\pm 50^{\circ}$ and $\pm 90^{\circ}$ were 109 $\mathrm{dB}$ and $107 \mathrm{~dB}$ respectively. This pattern is essentially identical to the forward mode produced by NBS System 1 but requires only two power amplifiers instead of four and should also be detectable at three times the range of the conventional electronic siren. The level produced by System 2 in the intersection mode is shown in figure 13 . At $\pm 50^{\circ}$ it is again about 122 $\mathrm{dB}$, or $10 \mathrm{~dB}$ higher than the conventional electronic siren at the same angle. 


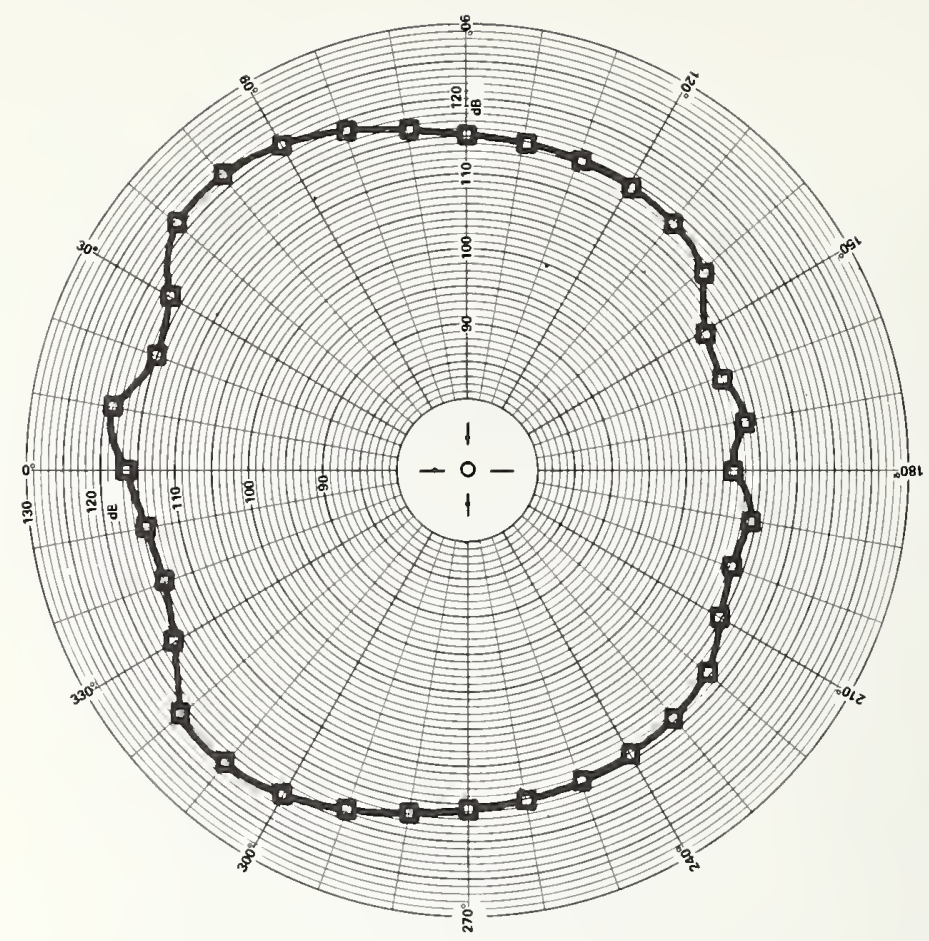

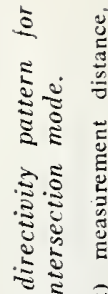

$\Xi .5 \infty$

ละ

ลั.

ชั่

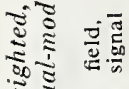

ङ 은은

से

ปิ

इक

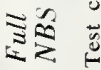

9

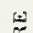

重

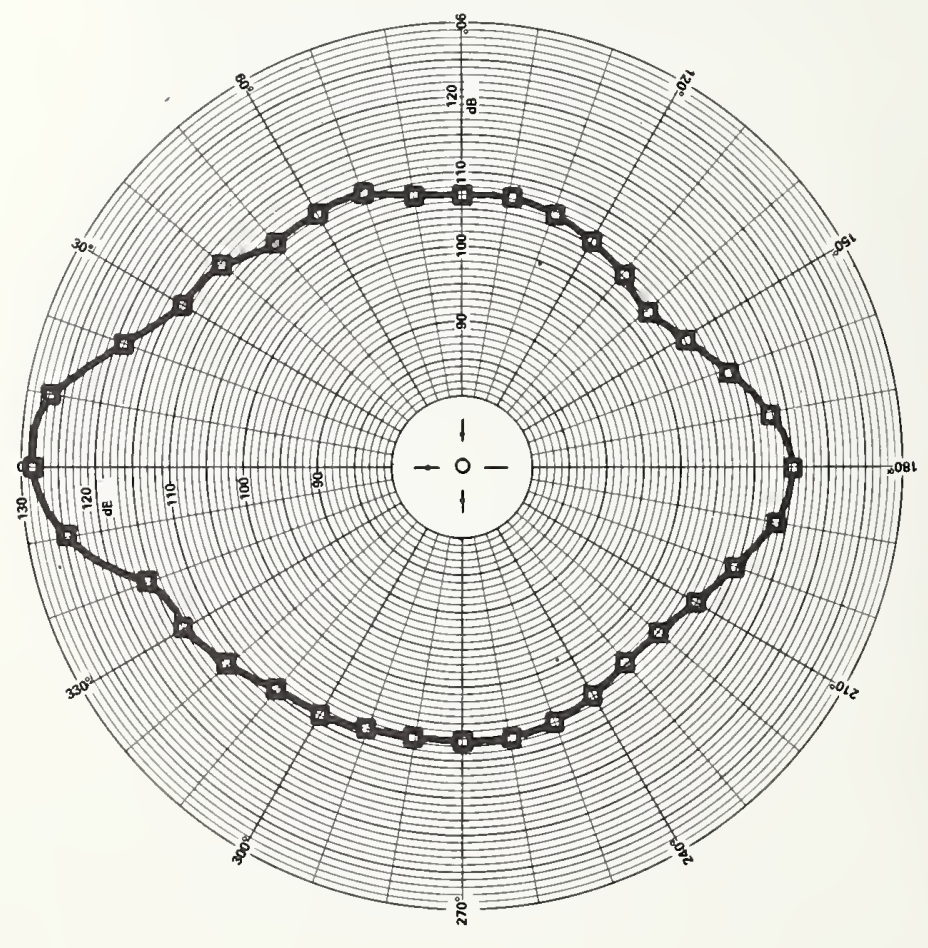

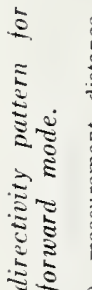

政

․․

ธิ

:

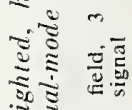

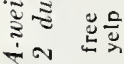

เิธี

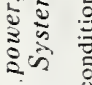

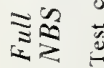

บ

兽 


\subsection{Testing the Acoustical Effects of Warning Lights Mounted on Both Ends of Siren Array}

Emergency vehicle sirens are generally used in conjunction with flashing warning lights. Most of the tests in the NBS anechoic room were made without these warning lights. The very small acoustical effect of warning lights mounted near the ends of the NBS siren array are shown in figures 14 and 15 . Note that at most of the data points the differences in average levels were small, and were imperceptible in the directions of interest $\left(0^{\circ}\right.$ and $\left.\pm 50^{\circ}\right)$.

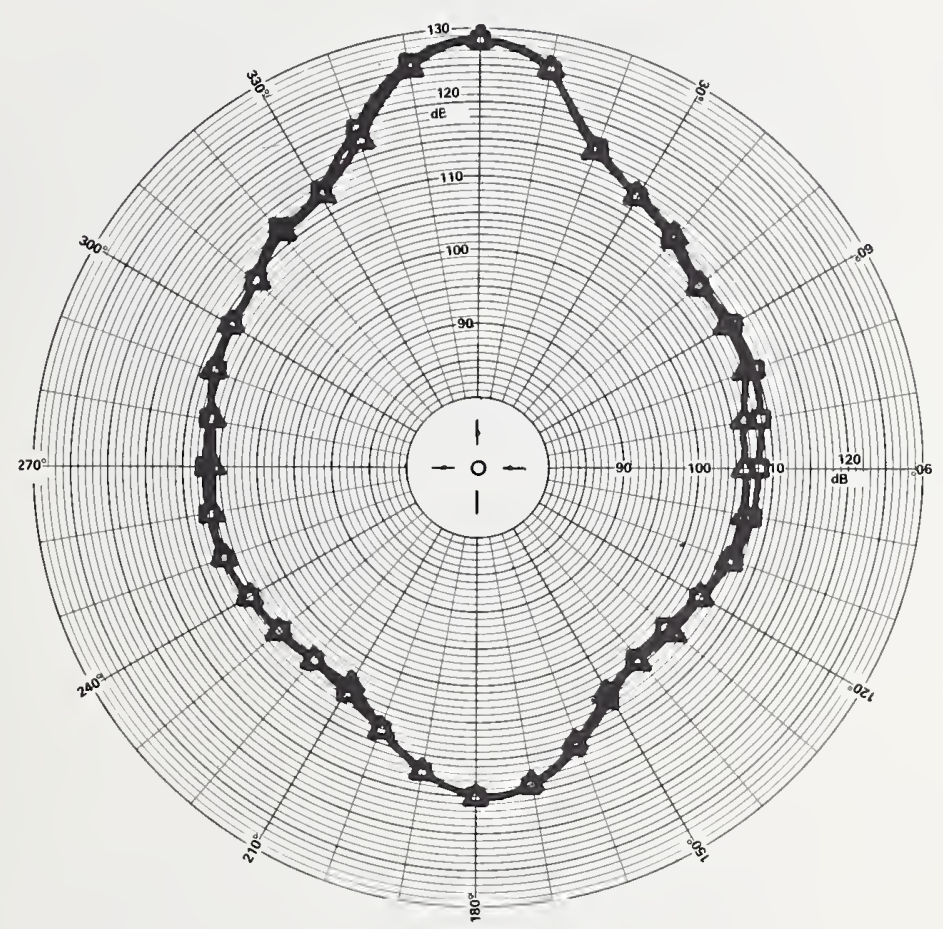

Figure 14. Effect of warning lights on full power, A-weighted, horizontal directivity pattern for NBS System 2 dual-mode siren in fortuard mode.

Test conditions: free field, $3 \mathrm{~m}(9.8 \mathrm{ft})$ measurement distance,
yelp signal

$\square$ System 2 alone

$\triangle$ System 2 with warning lights

\subsection{The Effect of Loudspeaker Size on Siren Array Directivity Pattern}

A set of large folded horns was connected to the 100 watt drivers in place of the compact folded horns described earlier in this report. These new horns were $7 \mathrm{~cm}(2.8$ in) longer than the compact version and were circular $(22 \mathrm{~cm}$ diameter) rather than rectangular like the compact horns. As can be seen in figure 16 both sides of the two center horns and one side of the outer horns had to be partially cut off to achieve the desired $15.2 \mathrm{~cm}$ ( $6.0 \mathrm{in}$ ) spacing between horns.

A comparison of the sound levels (yelp signal) produced by the two sets of folded horns is shown in figures 17 through 20 . For both systems 1 and 2 the larger horns increased the output on axis by $2 \mathrm{~dB}$ in the forward mode. In the intersection mode for both systems 1 and 
2. the larger horns increased the sound pressure level by $1 \mathrm{~dB}$ at $\pm 50^{\circ}$ and 2 to $3 \mathrm{~dB}$ over a $90^{\circ}$ sector centered about the $0^{\circ}$ line. The larger horns generally produced equal or lower sound pressure levels in the non-useful directions beyond $\pm 90^{\circ}$.

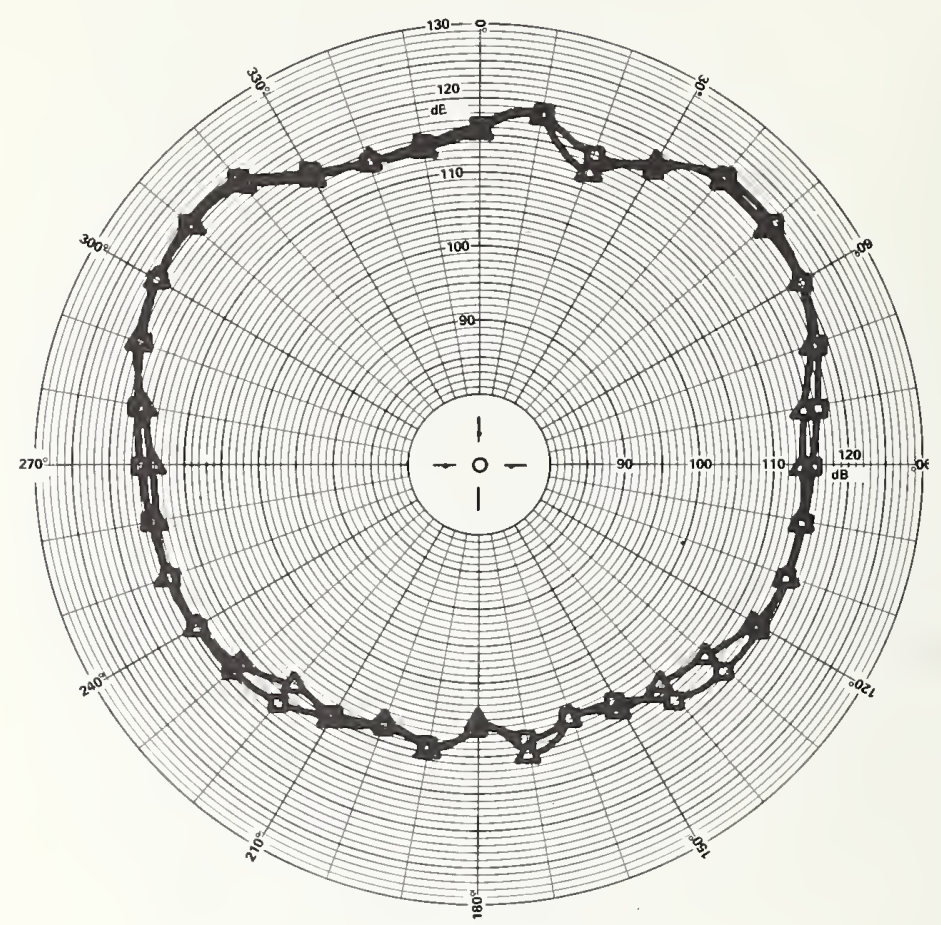

Figure 15. Effect of warning lights on full power, A-weighted, horizontal directivity pattern for NBS System 2 dual-mode siren in intersection mode.

Test conditions: free field, $3 \mathrm{~m}(9.8 \mathrm{ft})$ measurement distance,
yelp signal

$\square$ NBS System 2 alone

$\triangle$ System 2 with warning lights

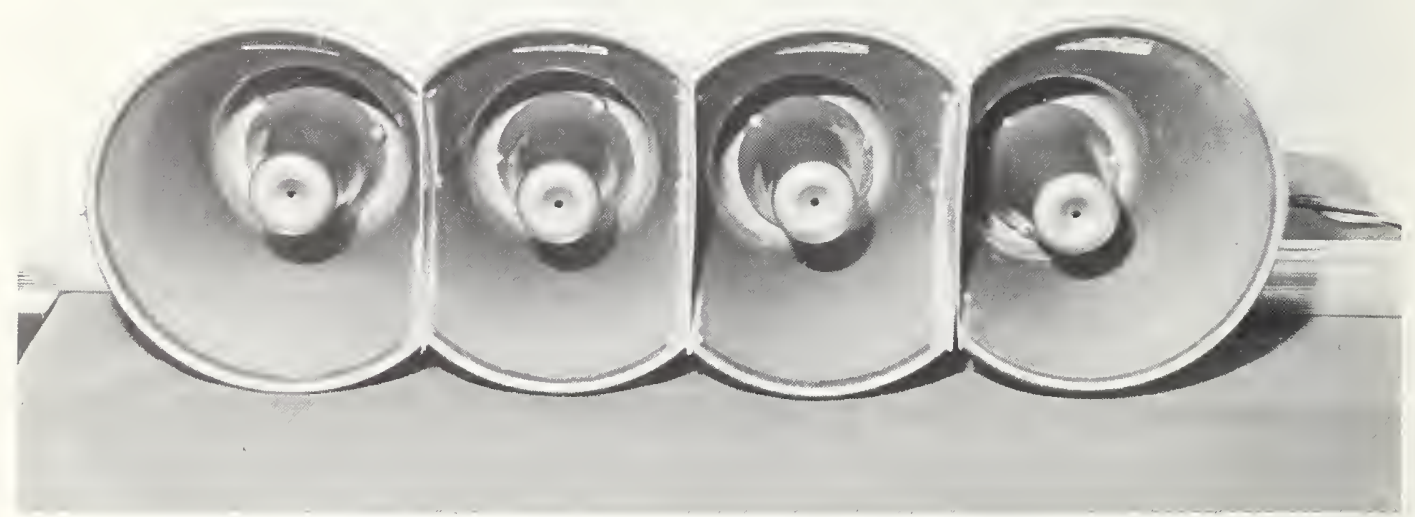

Figure 16. NBS large horn siren array with $15.2 \mathrm{~cm}$ (6.0 in) center-to-center spacing. 


$$
\begin{aligned}
& 0 \\
& 0 \\
& 0
\end{aligned}
$$




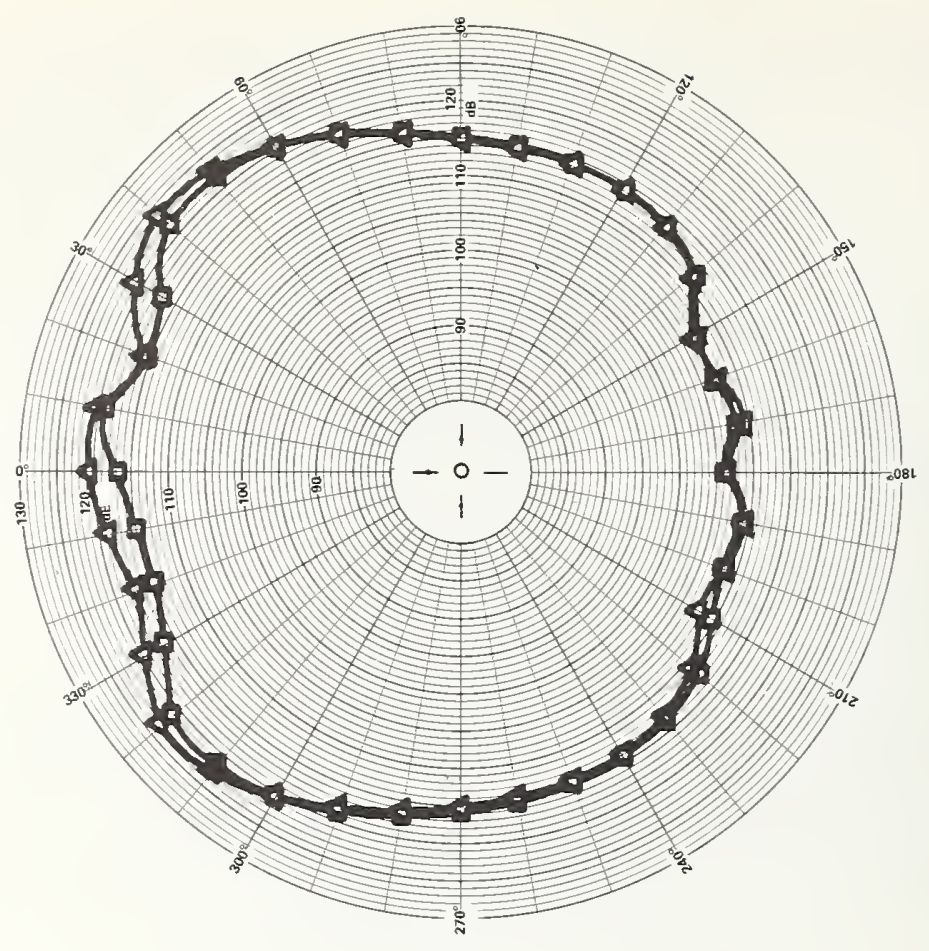

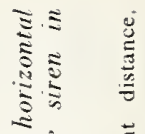

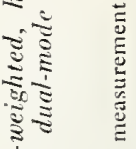

$-i \frac{\pi}{2}$

$\frac{2}{2} \frac{0}{2} \quad x$

एक $\mathrm{E}$

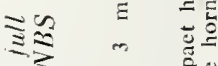

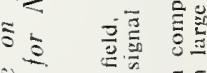

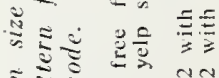

इ

-

¿

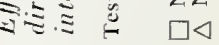

$\dot{\mathrm{s}}$

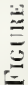

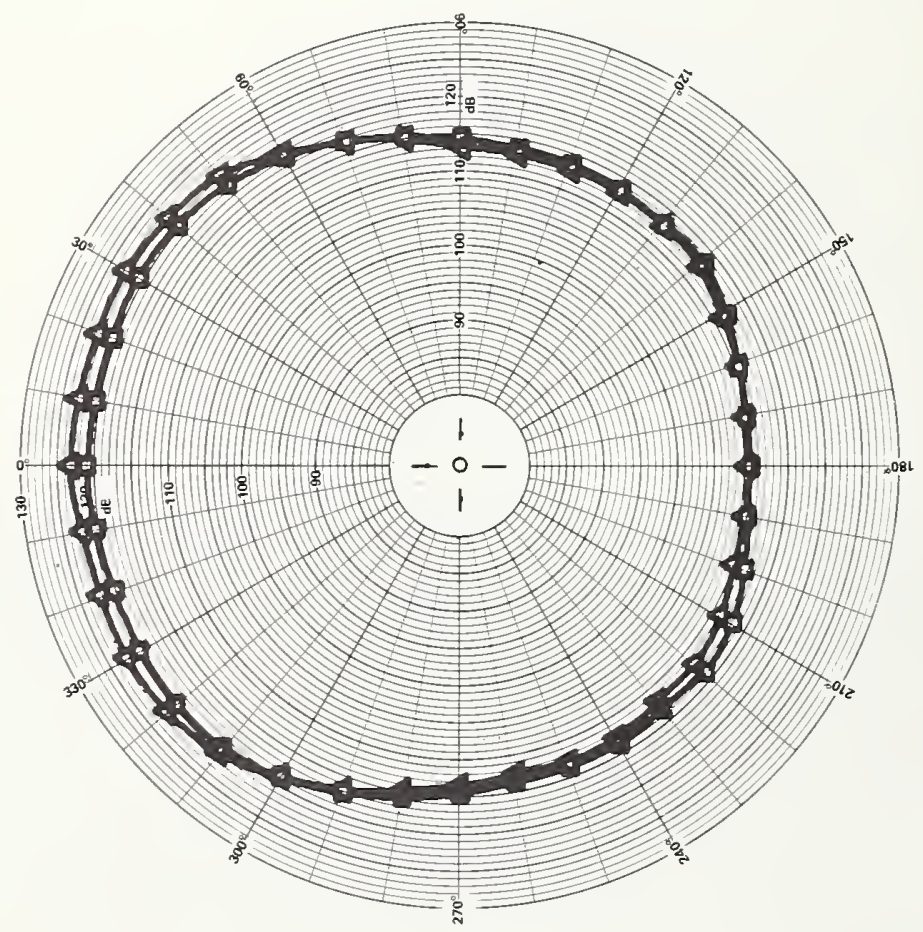

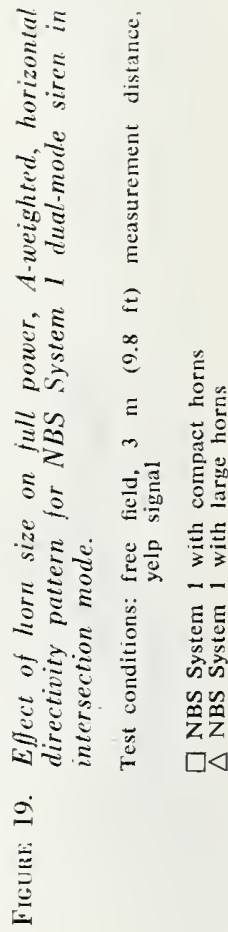




\section{LOW POWER TESTS OF SIRENS ON A FULL SIZE SEDAN}

The NBS dual-mode siren systems, as well as a conventional electronic siren, were tested with a low-power yelp signal (to avoid complaints from the local community) on a circular concrete pad at Ft. Belvoir, Va. The vehicle was parked on the center of the pad in the direction that minimized the occurrence of reflections of the siren sound from a nearby building and distant hills. (See figs. 21 and 22.)

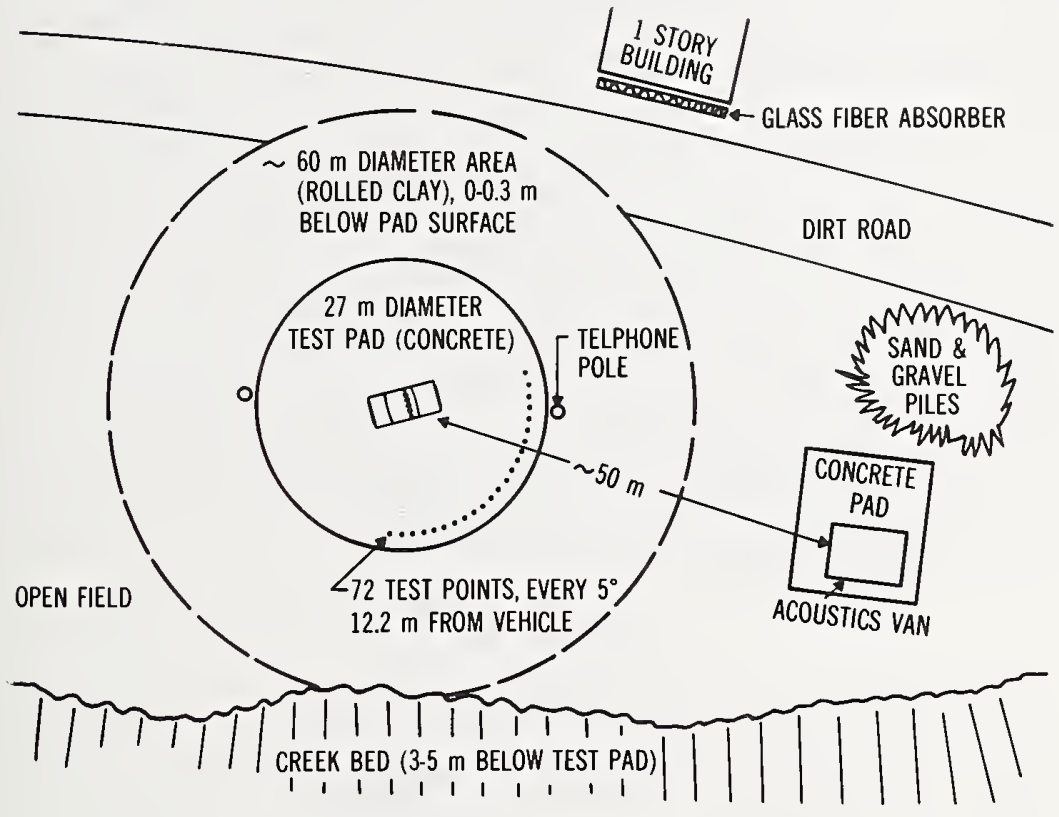

Figure 21. Test site for sirens on vehicle.

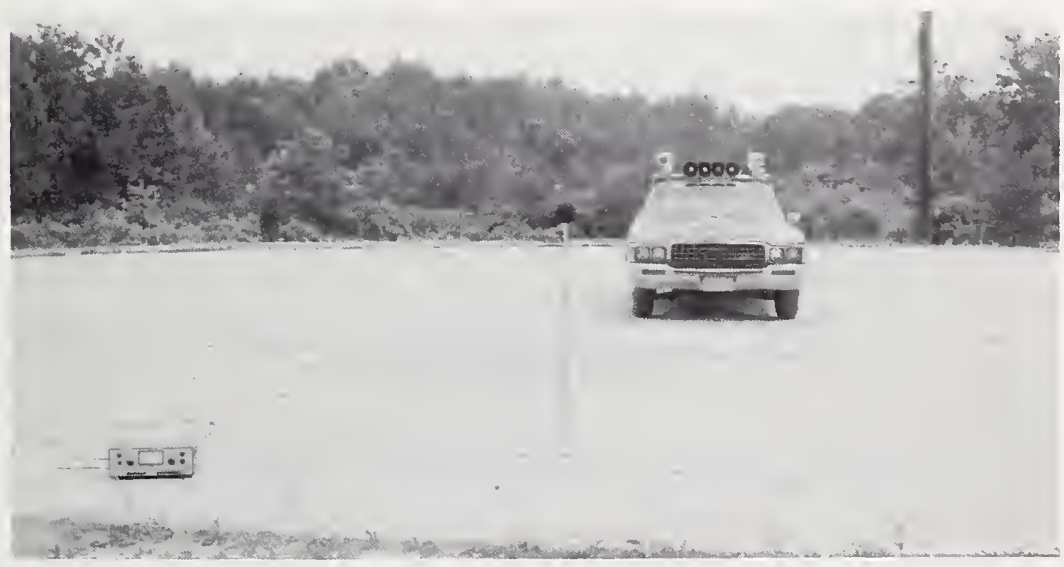

Figure 22. NBS dual-mode siren at outdoor test site. 
The system used to measure and record 1/3-octave band and A-weighted sound pressure levels was the same as shown in figure 6 except that a one inch microphone was used for greater sensitivity. During the initial runs, the microphone was placed on one of the 72 test

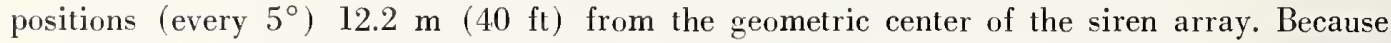
smooth curves plotted through the data points were well defined by using every other data point, to speed up the measurement process later runs were made with microphone positions every $10^{\circ}$ around the siren. The signal from the $1.2 \mathrm{~m}(4 \mathrm{ft})$ high microphones was passed through the preamplifier and main amplifier to the $1 / 3$-octave band real time analyzer (RTA) and minicomputer, which were inside a van about $50 \mathrm{~m}(164 \mathrm{ft})$ away.

The minicomputer was programmed to have the RTA sample the test signal 200 times at each test position. The samples were taken every 0.1 second for yelp signals and every 0.3 second for wail signals and for NBS System 1 in the sweep mode. An average A-weighted level was determined by computing the mean square value of the A-weighted sound pressures. The average A-weighted value for each position, along with the instantaneous A-weighted, linear, and $1 / 3$-octave band data, were stored on digital magnetic tape. The data analysis system was calibrated with a pistonphone before and after each run of 36 (or 72) positions.

The sirens were connected to the regular vehicle battery. To maintain a constant de voltage the vehicle engine was kept running at a slow idle during the tests. Using a hand-held precision sound level meter, the highest A-weighted sound pressure level measured at any of the test positions with the vehicle running but no siren in operation was found to be $56 \mathrm{~dB}$. Typical ambient readings with the car engine not running were from 40 to $50 \mathrm{~dB}$. As shown in figure 23 the $1 / 3$-octave band spectrum of the siren signal in front of the car at $12.2 \mathrm{~m}$ ( $40 \mathrm{ft}$ ) was more than $20 \mathrm{~dB}$ higher than the background noise level. This high signalto-noise level was maintained throughout the outdoor tests.

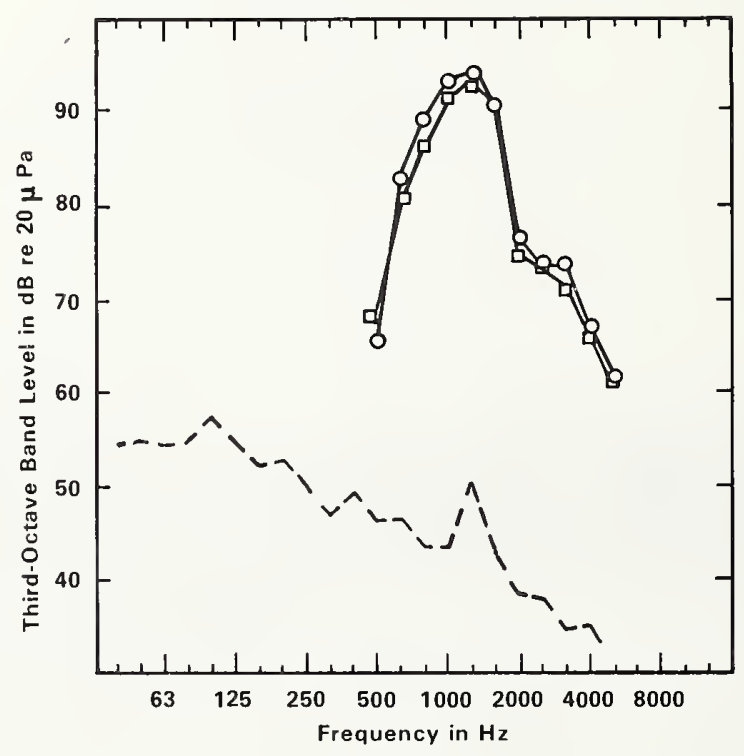

Figure 23. Third-octave band spectrum of background noise and NBS siren signals at outdoor test site. 


\subsection{Attenuation Versus Distance from Sirens}

On-axis $\left(0^{\circ}\right)$ measurements were also made at $24.4 \mathrm{~m}(80 \mathrm{ft}), 36.6 \mathrm{~m}(120 \mathrm{ft})$ and 48.8 $\mathrm{m}(160 \mathrm{ft})$ from the center of the siren array using a microphone located $1.2 \mathrm{~m}(4 \mathrm{ft})$ above ground level. Each average A-weighted level, normalized to the anechoic room level at $3.0 \mathrm{~m}(9.8 \mathrm{ft})$, is plotted in figure 24 . The triangles show the drop in level with distance for a conventional 100-watt electronic siren. The squares represent sound pressure levels for the NBS siren System 1 in the forward mode. The circles show the results for System 1 in the intersection mode. Except for increased levels at $12.2 \mathrm{~m} \mathrm{(40} \mathrm{ft)} \mathrm{due} \mathrm{to} \mathrm{in-phase} \mathrm{signal} \mathrm{re-}$ flections from the concrete pad, the data closely follow the theoretical attenuation line for spherical spreading of sound waves in a free field.

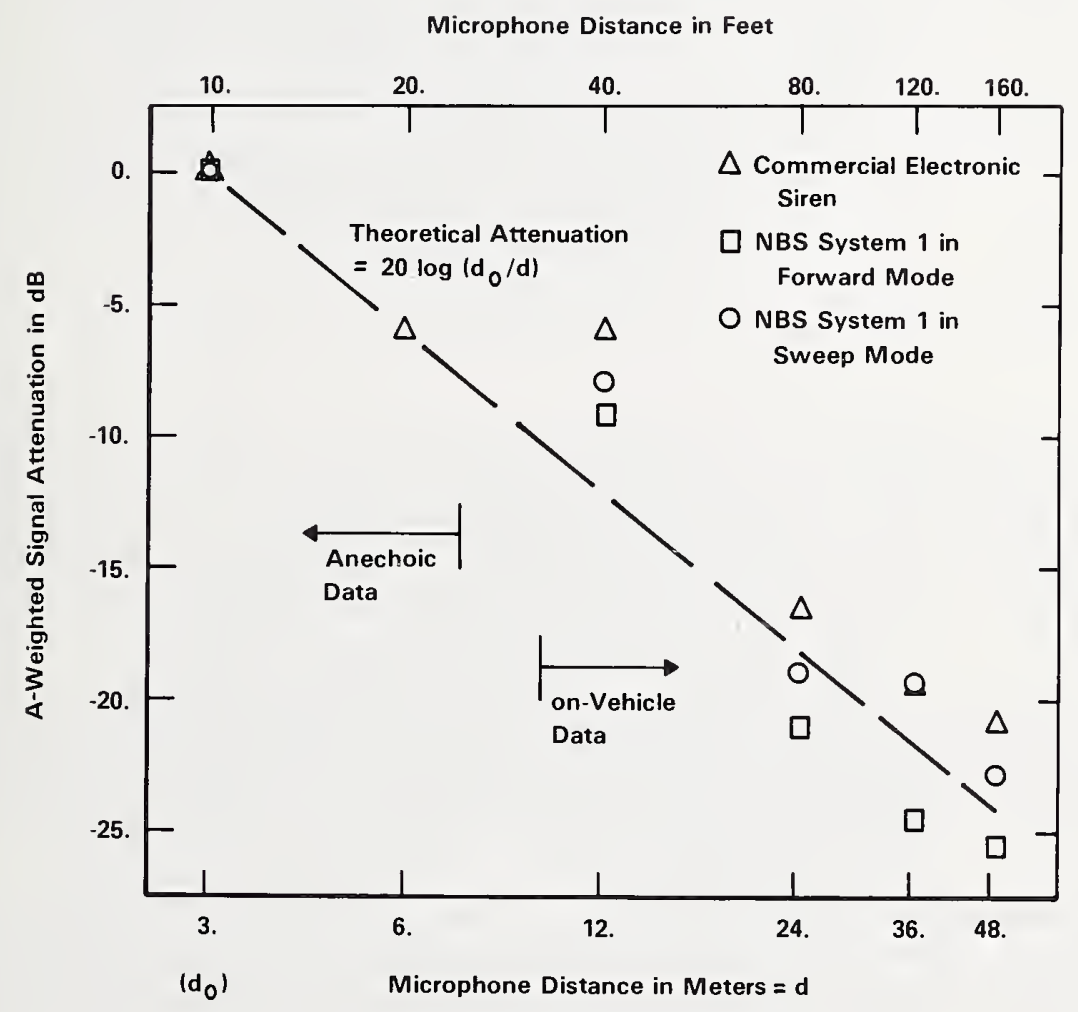

Figure 24. Siren signal attenuation as a function of distance.

\subsection{Scaling Low Power Test Results Measured on a Vehicle to the Equivalent Full Power Output Results}

The relationship between the root-mean-square ( $\mathrm{rms}$ ) voltage applied to one of the 100 watt compact siren loudspeakers in the anechoic room and sound pressure level output at 3 meters is shown in figure 25 for a $1000 \mathrm{~Hz}$ sine wave. Because the function is nearly linear from 0.1 volts $\mathrm{rms}$ to 32 volts $\mathrm{rms}$ (which is equivalent to 100 watts full power), the field test data were easily scaled up from measured low power levels to expected full power levels. 


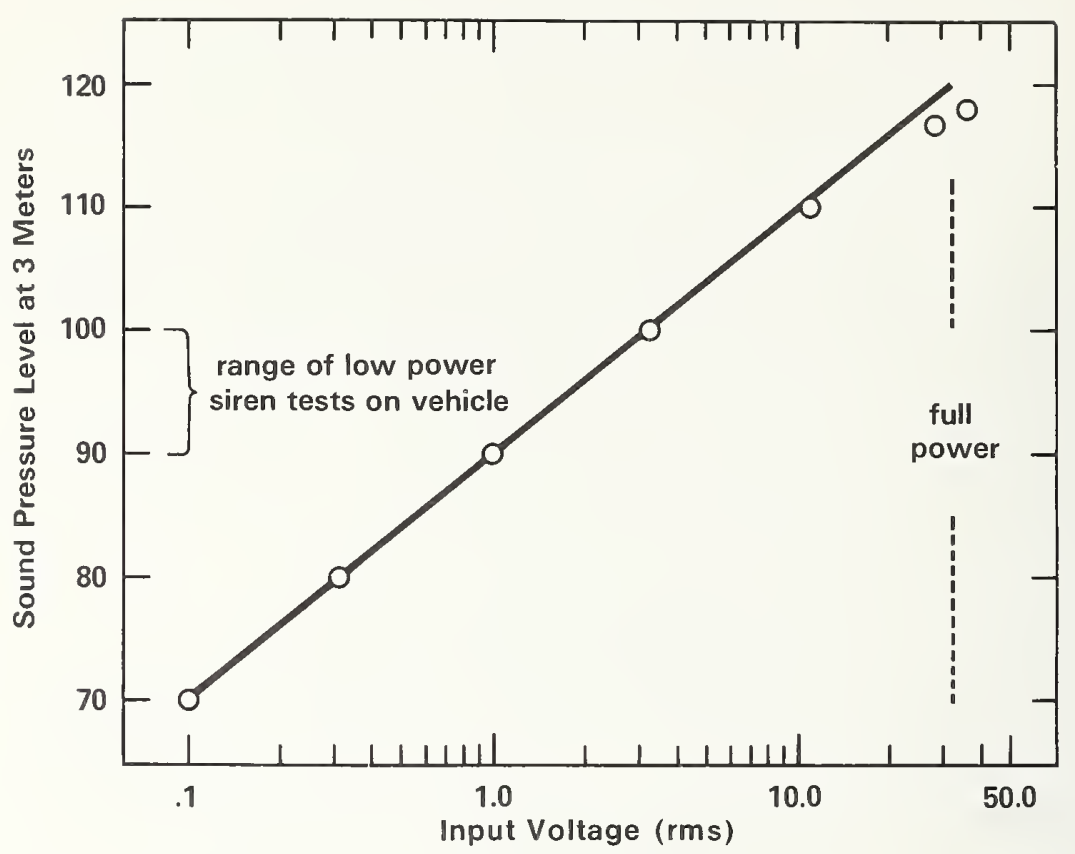

Figris: 25. Free field response of electromic siren speaker to a $1000 \mathrm{~Hz}$ sine ware.

In this section all polar plots showing directivity patterns were scaled up to full power levels from data obtained from a microphone located at $1.2 \mathrm{~m}(4.0 \mathrm{ft})$ above ground level and at a horizontal distance of $12.2 \mathrm{~m}(40 \mathrm{ft})$ from the siren mounted on the vehicle. Except for the data on the commercial electronic siren, all on-vehicle tests were made with the large folded horns pictured in figure 16 and all on-vehicle tests included the roof mounted warning lights.

The time-averaged (over 20 seconds) directivity pattern of the commercial 100-watt electronic siren on the roof of a full size sedan is given in figure 26. Because of reflections from the car, from warning lights on the mounting bar, and from the concrete pad on which the car was positioned, the pattern is not as smoothly shaped as the free-field pattern in figure 9.

The scaled-to-full power response of the NBS System 1 dual-mode siren on the vehicle is presented in figure 27 for the forward mode. The A-weighted sound level of the NBS siren was about $122 \mathrm{~dB}$ on axis $\left(\right.$ at $0^{\circ}$ ) while for the conventional 100-watt electronic siren the maximum sound pressure level was $112 \mathrm{~dB}$. The differential is again $10 \mathrm{~dB}$, although the scaledto-full power levels at $0^{\circ}$ are both $6 \mathrm{~dB}$ lower than the free-freld levels.

Figure 28 shows the response of the System 1 siren (scaled to full power) in the intersection mode of operation. The intersection mode pattern, as averaged over several entire angular sweeps, produced levels about $7 \mathrm{~dB}$ higher than those of the conventional 100-watt electronic siren at $\pm 50^{\circ}$ from the on-axis line.

In order to determine the instantaneous beam pattern for System $I$ as the beam is swept spatially, temporary circuitry was used to enable fixing the steering of the main beam in a desired direction. Figure 29 shows the average radiation pattern when the time delays were fixed to point the main beam at $30^{\circ}$ off axis $\left(0^{\circ}\right)$. Figures 30 and 31 depict patterns steered to $60^{\circ}$ and $90^{\circ}$, respectively, using theoretically derived time delays. Note that the main 


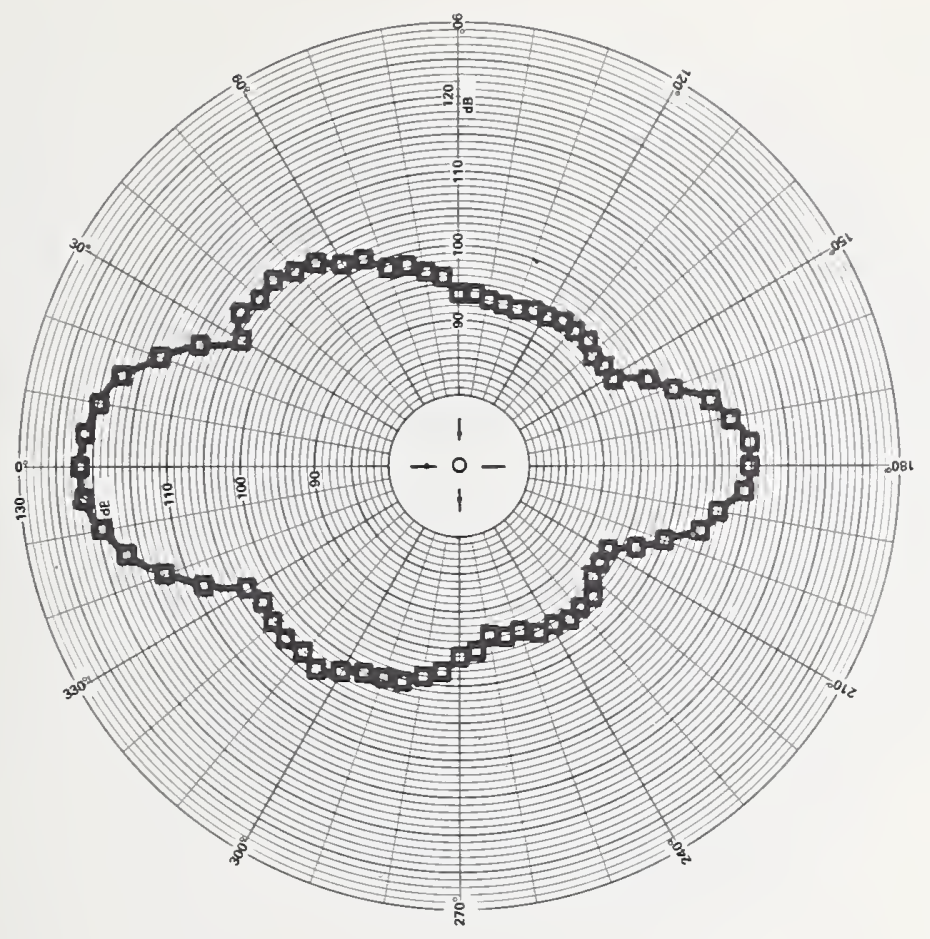

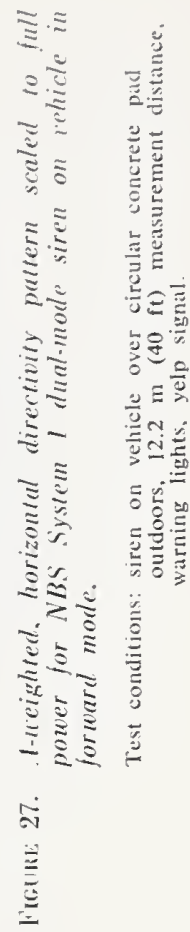

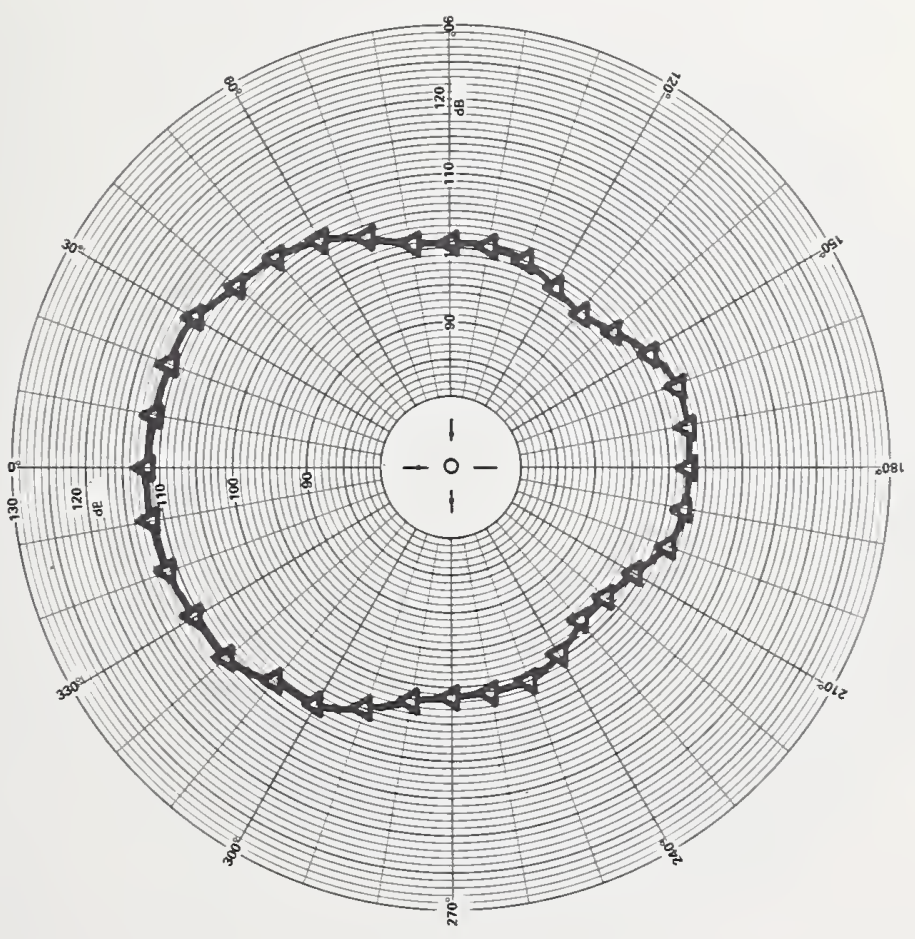

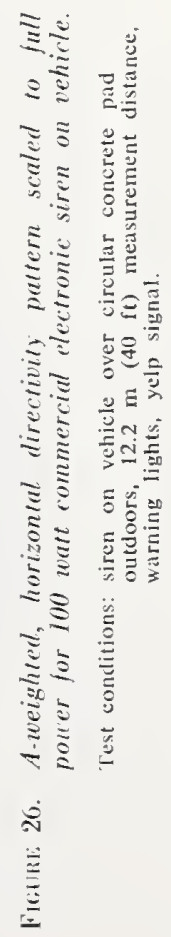



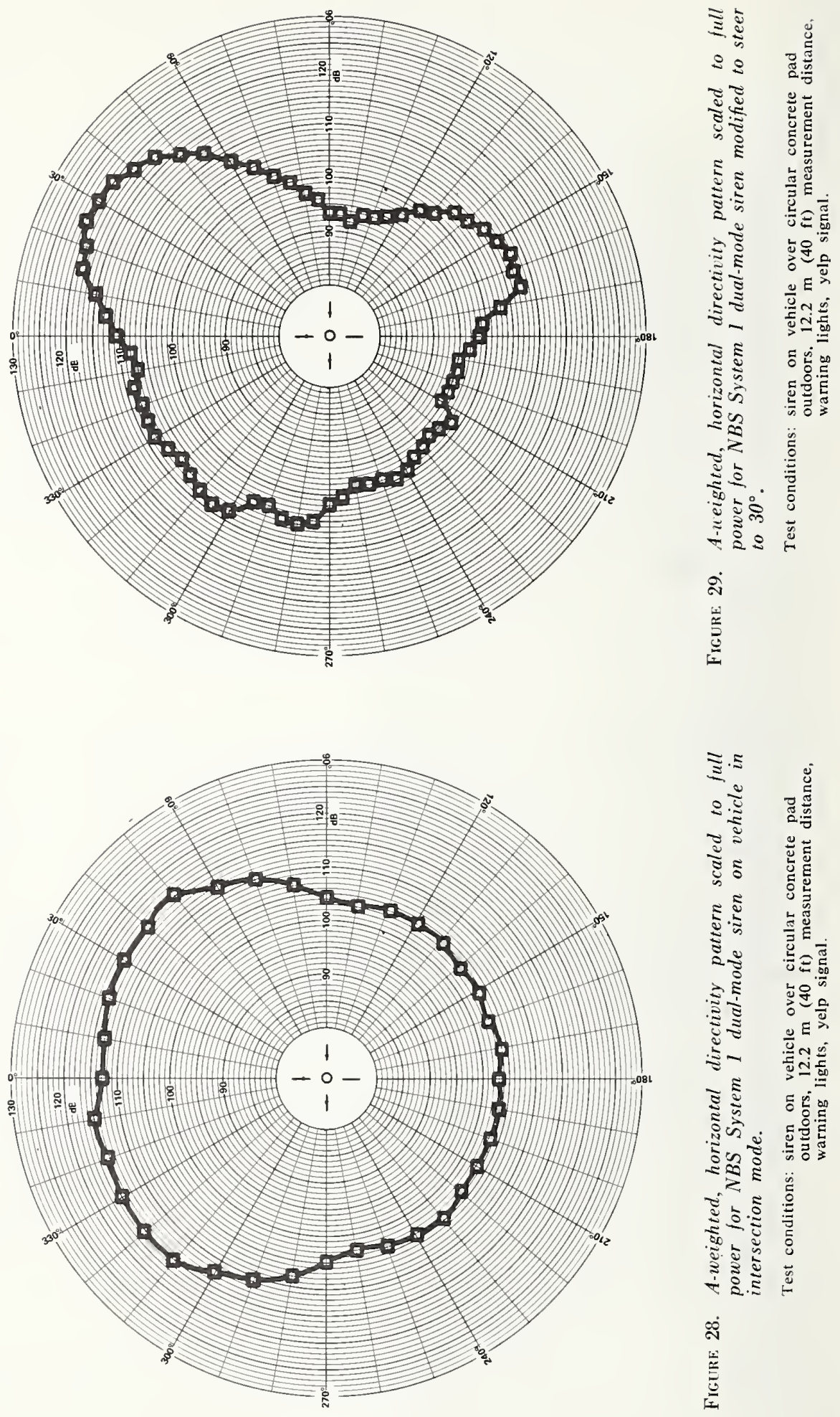

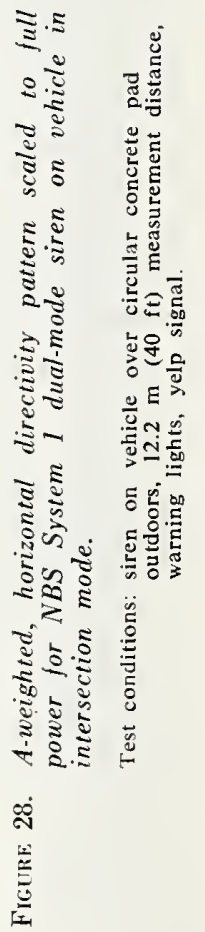




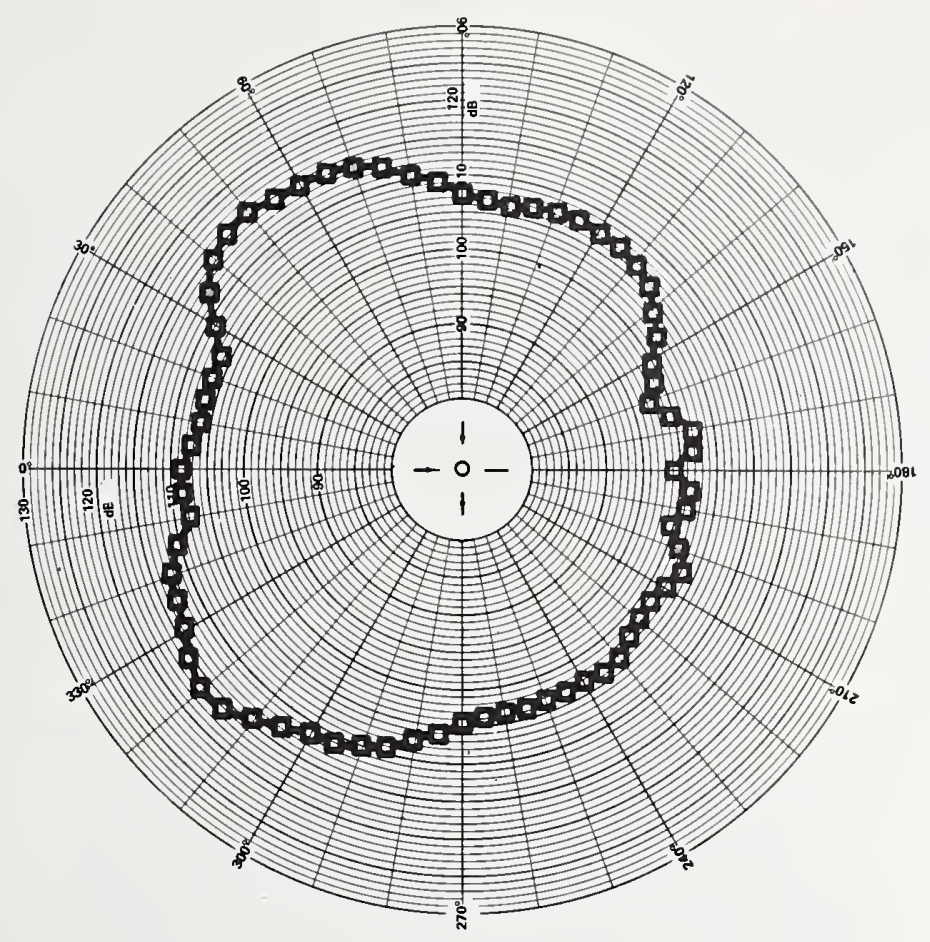

छั

2: 8

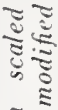

ฐ.

芯

¿

थ

ह

¿

¿

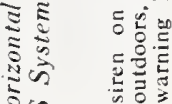

si के

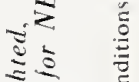

ษ。:

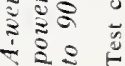

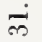

要

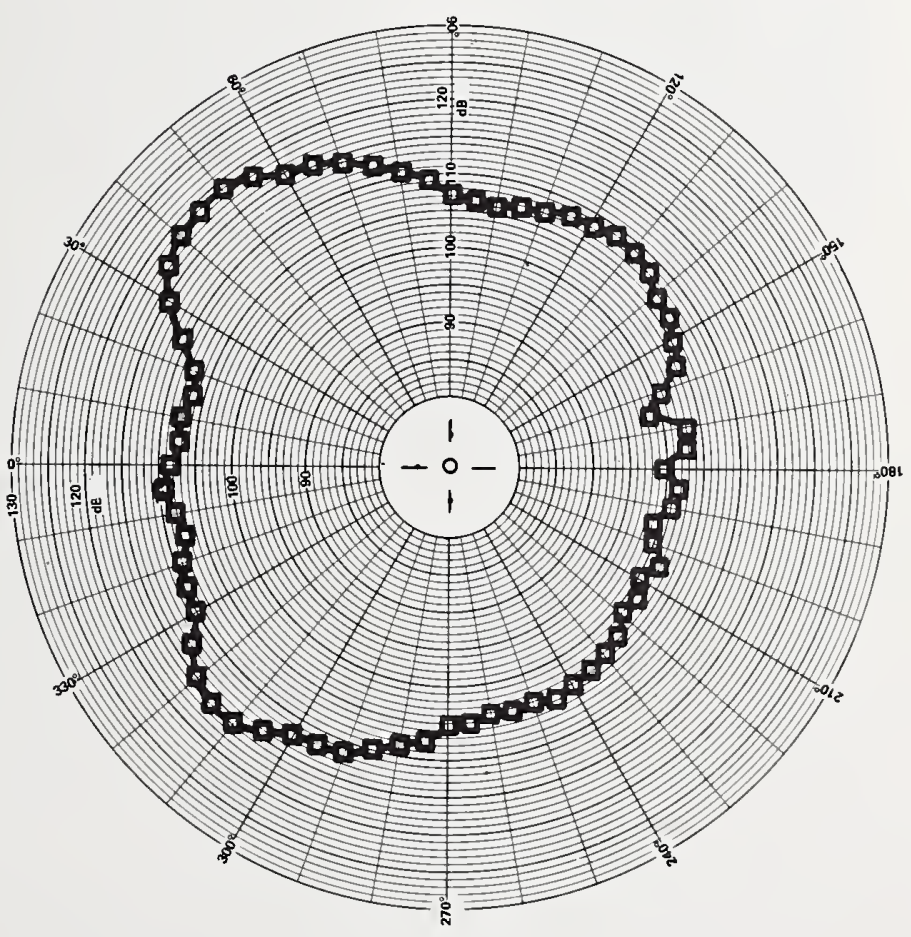

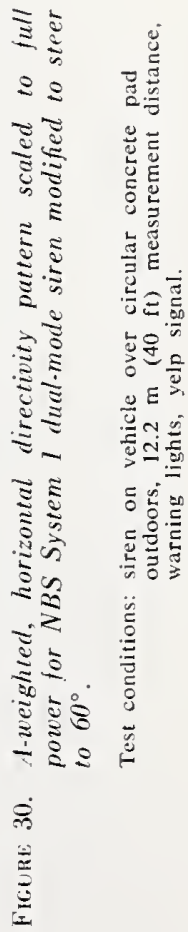


beam becomes less well-defined as the steering approaches $90^{\circ}$ and the side lobes around $325^{\circ}$ increase because the array is then operating in an endfire mode. The actual maximum A-weighted sound levels occurred at $45^{\circ}$ and $50^{\circ}$ for these two cases because the loudspeakers were not simple sources but had their own directivity patterns. In normal operation in the intersection mode, however, the beam is swept from $-90^{\circ}$ to $+90^{\circ}$ and back to $-90^{\circ}$ in $1.4^{\circ}$ increments over a period that is adjustable from less than one second to more than 15 seconds.

As shown in figures 10 and 12, which depict measurements taken in the anechoic room, the responses of Systems 1 and 2 were nearly identical. Therefore, the "forward" mode of NBS System 2 was not run in the field.

The intersection mode for System 2 was measured in the field on a vehicle and the scaled results are given in figure 32. This was a steady-state pattern, instead of the swept beam of System 1. The level toward the front, $0^{\circ}$, was about $2 \mathrm{~dB}$ lower than that from the conventional 100 watt electronic siren. The sound pressure level at $\pm 50^{\circ}$ was $7 \mathrm{~dB}$ higher than that of the conventional electronic siren.

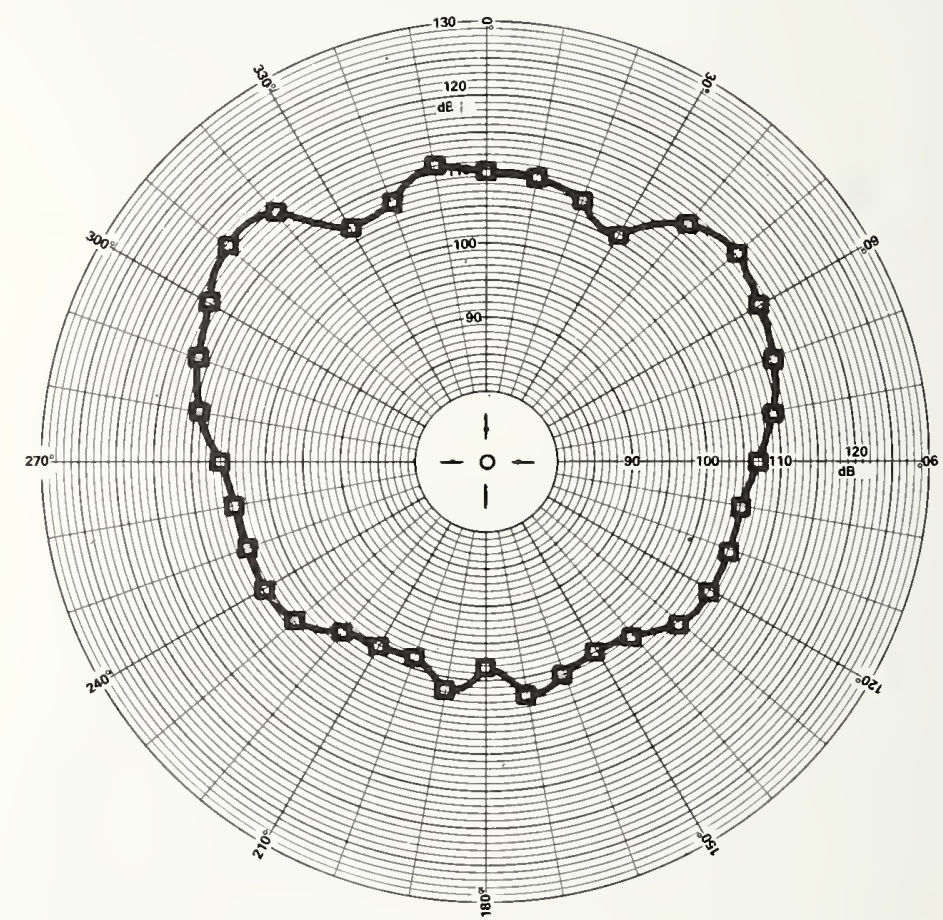

Figure, 32. A-weighted, horizontal directivity pattern scaled to full power for NBS System 2 dual-mode siren on vehicle in intersection mode.

Test conditions: siren on vehicle over circular concrete pad outdoors, $12.2 \mathrm{~m}$ (40 ft) measurement distance. warning lights, yelp signal.

\subsection{Comparison of the Wail and Yelp Directivity Patterns}

System 1 was also run using the wail siren signal. Figures 33 and 34 are almost identical to the patterns using the yelp signal (figs. 27 and 28). System 2 was run in the intersection mode using the wail signal and the results are shown in figure 35 . This pattern is nearly the same as that shown in figure 32 for the yelp signal. 


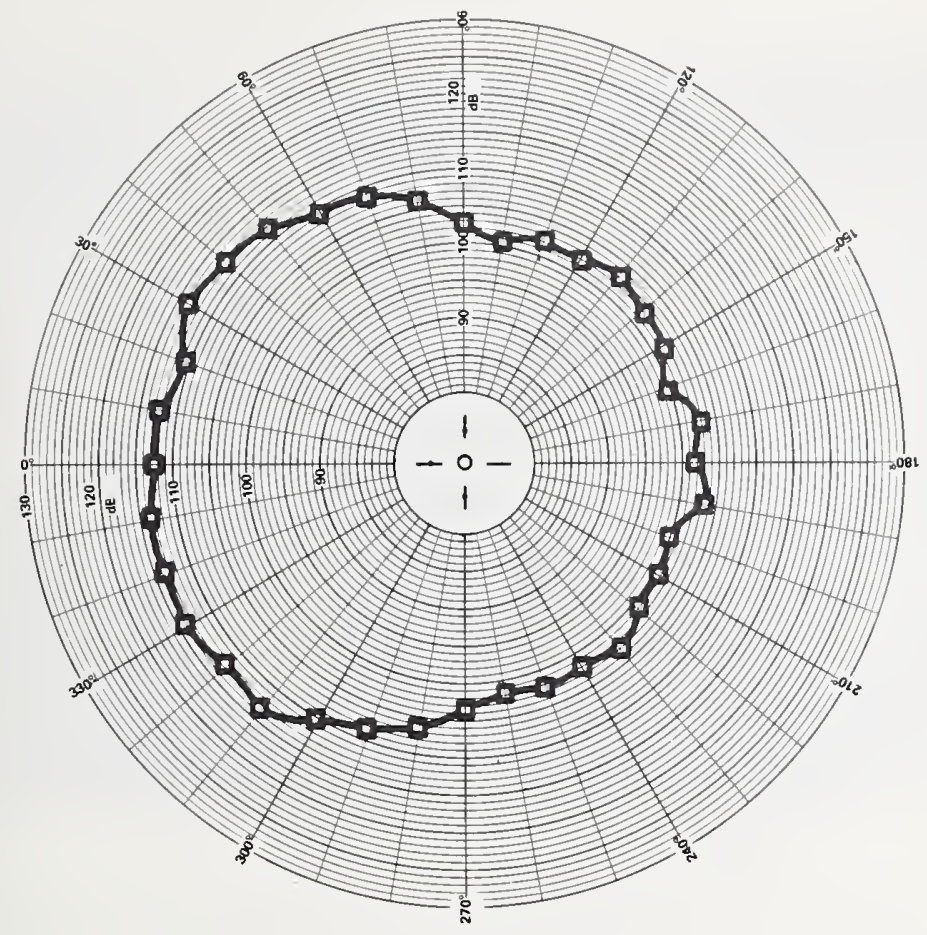

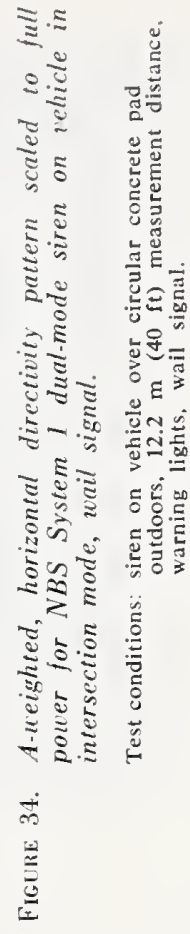

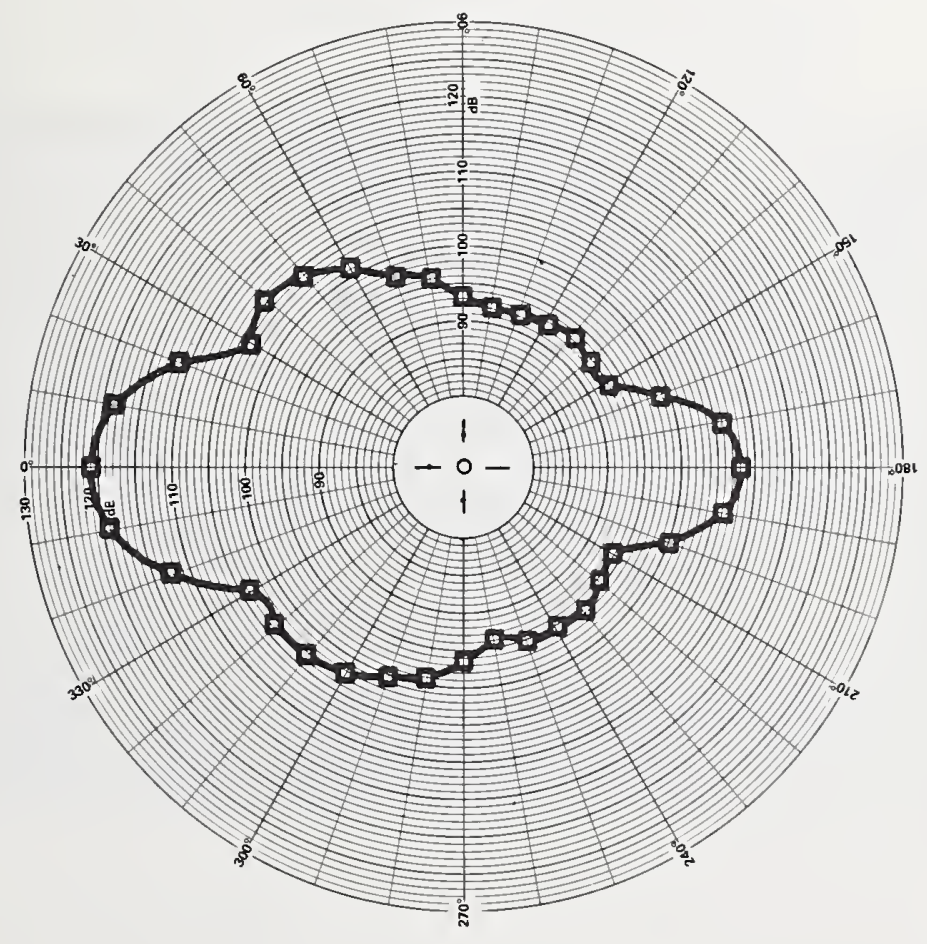

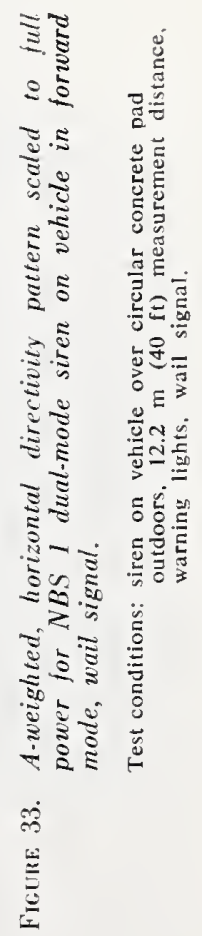




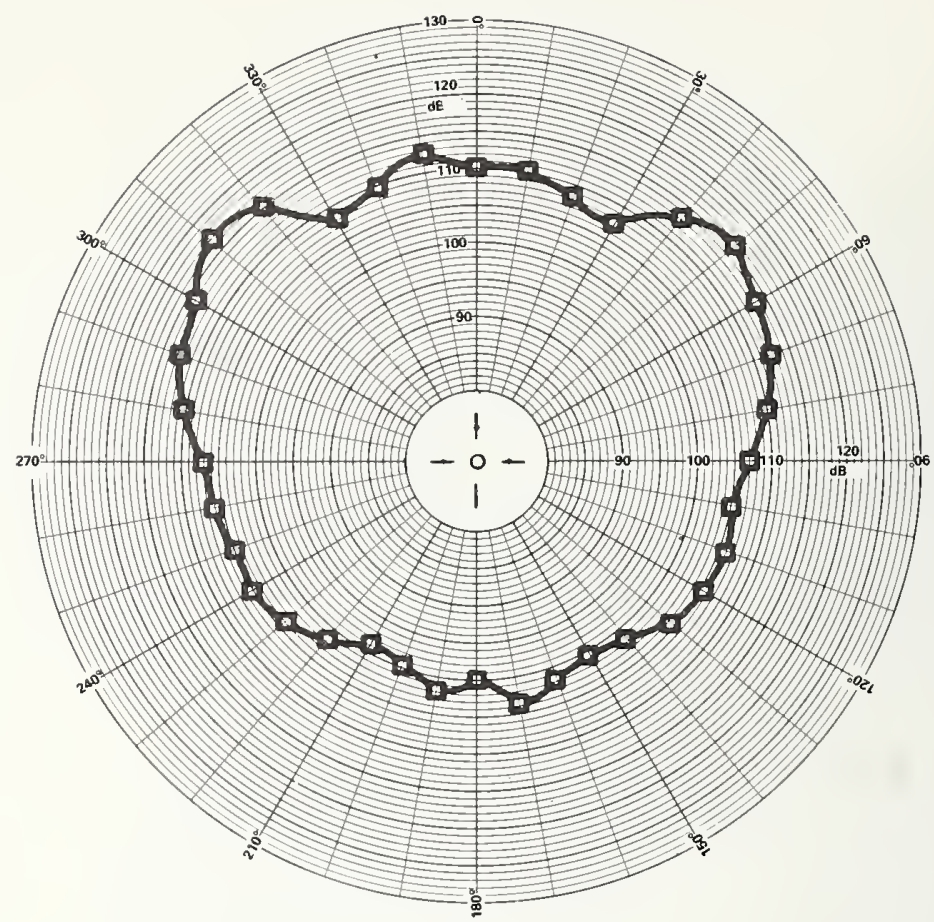

Figure 35. A-leighted, horizontal directivity pattern scaled to jull power for NBS System 2 dual-mode siren on vehicle in intersection mode, wail signal.

Test conditions: siren on vehicle over circular concrete pad outdoors, $12.2 \mathrm{~m}$ ( $40 \mathrm{ft})$ measurement distance. wail signal.

\section{CONCLUSIONS}

NBS designed, constructed, and measured the performance of a highly directional siren that could be electrically switched under manual control from a strong narrow forward-pointing beam of sound, for open highway usage, to a wider beam providing greater sound levels to the sides of an emergency vehicle, for use when approaching a roadway intersection.

The loudspeaker array is shown in figures 36 and 37. The loudspeakers were 100-watt commercial siren speakers spaced $15.2 \mathrm{~cm}$ (6.0 in) apart and were mounted on a roof rack of the type commonly used also to support emergency vehicle warning lights.

NBS developed a time delay electronic network. This network, in conjunction with a control module, four 100-watt amplifiers, and the four-element speaker array, produced an intense beam of sound that could be cyclically swept from left to right of the vehicle in $1.4^{\circ}$ steps or be fixed straight ahead of the vehicle. The scaled-to-full-power, time-average response

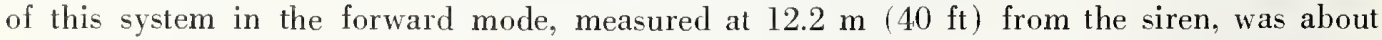
$10 \mathrm{~dB}$ higher than that of a conventional 100-watt electronic siren (see fig. 38). Since sound pressure is inversely proportional to distance from the siren, the NBS system should be detectable at three times the range of the conventional electronic siren. A similar comparison is made in figure 39 for the NBS system in the intersection mode of operation. In this mode, 


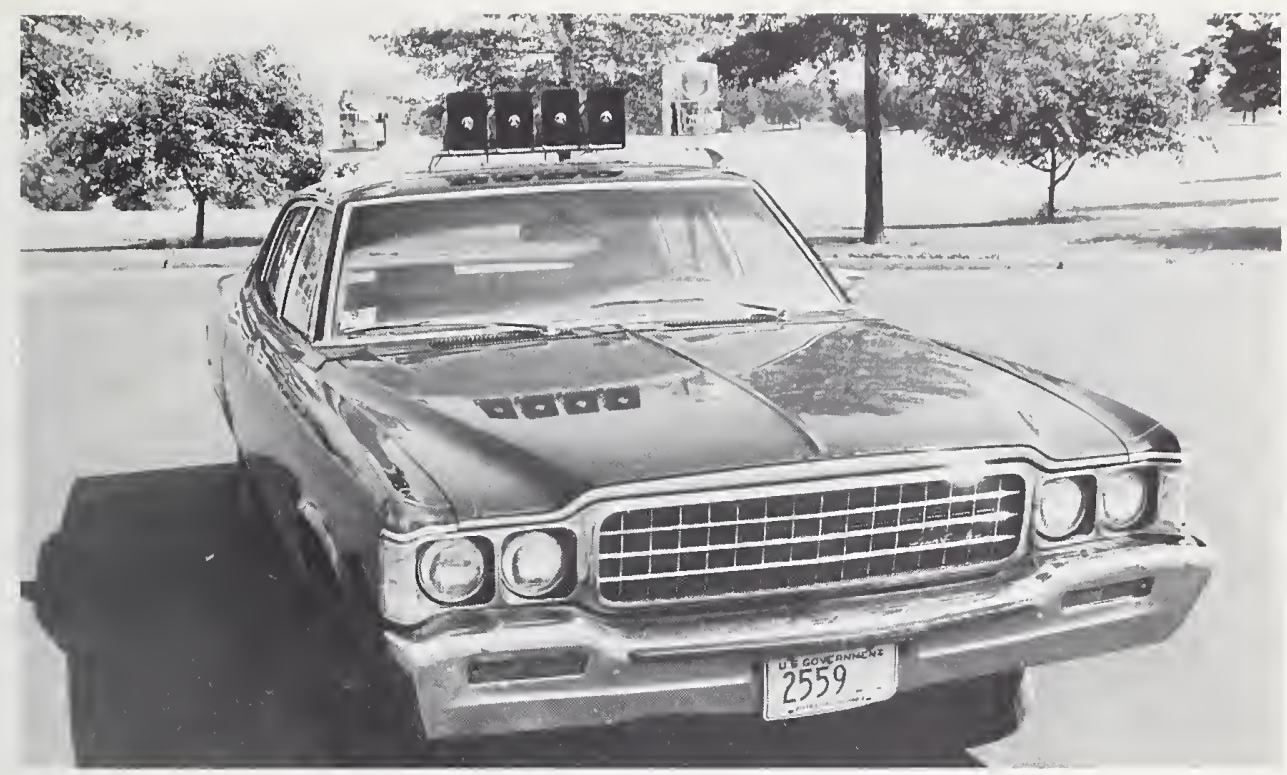

Figuk 36. Dualmode siren array on tehicle.

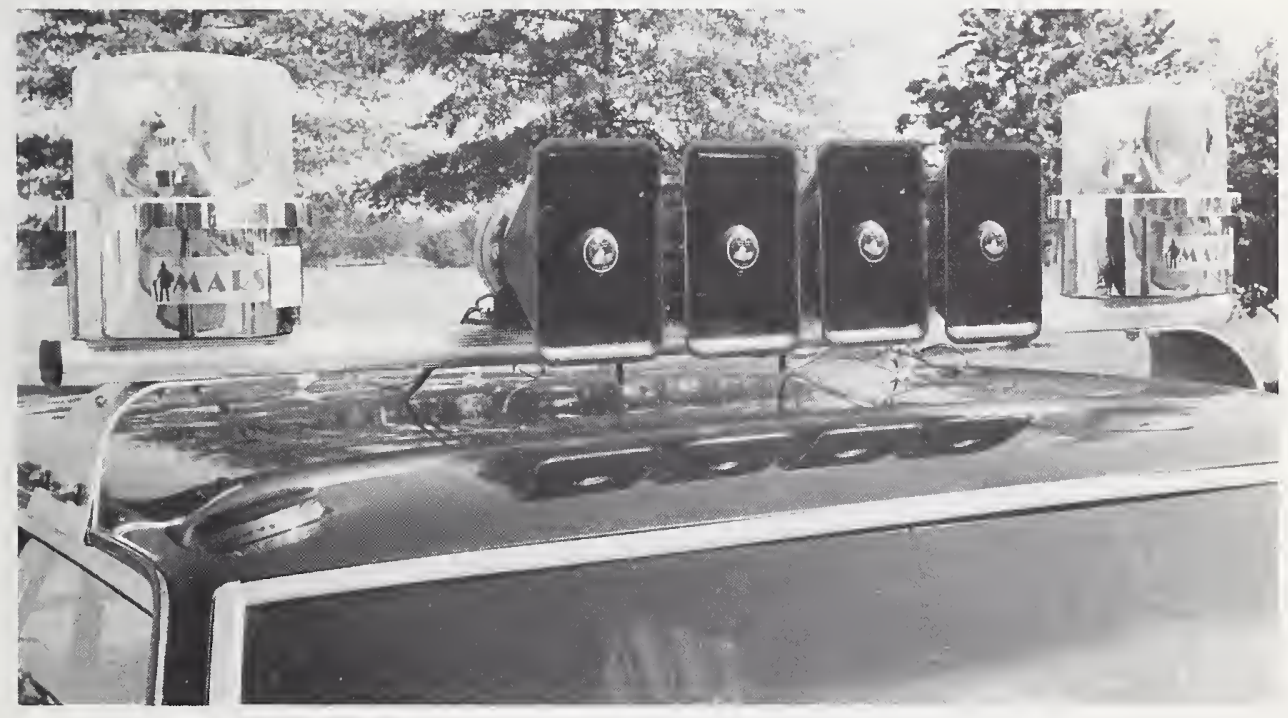

Figure 37. Closeup photograph of dual-mode siren array on vehicle. 

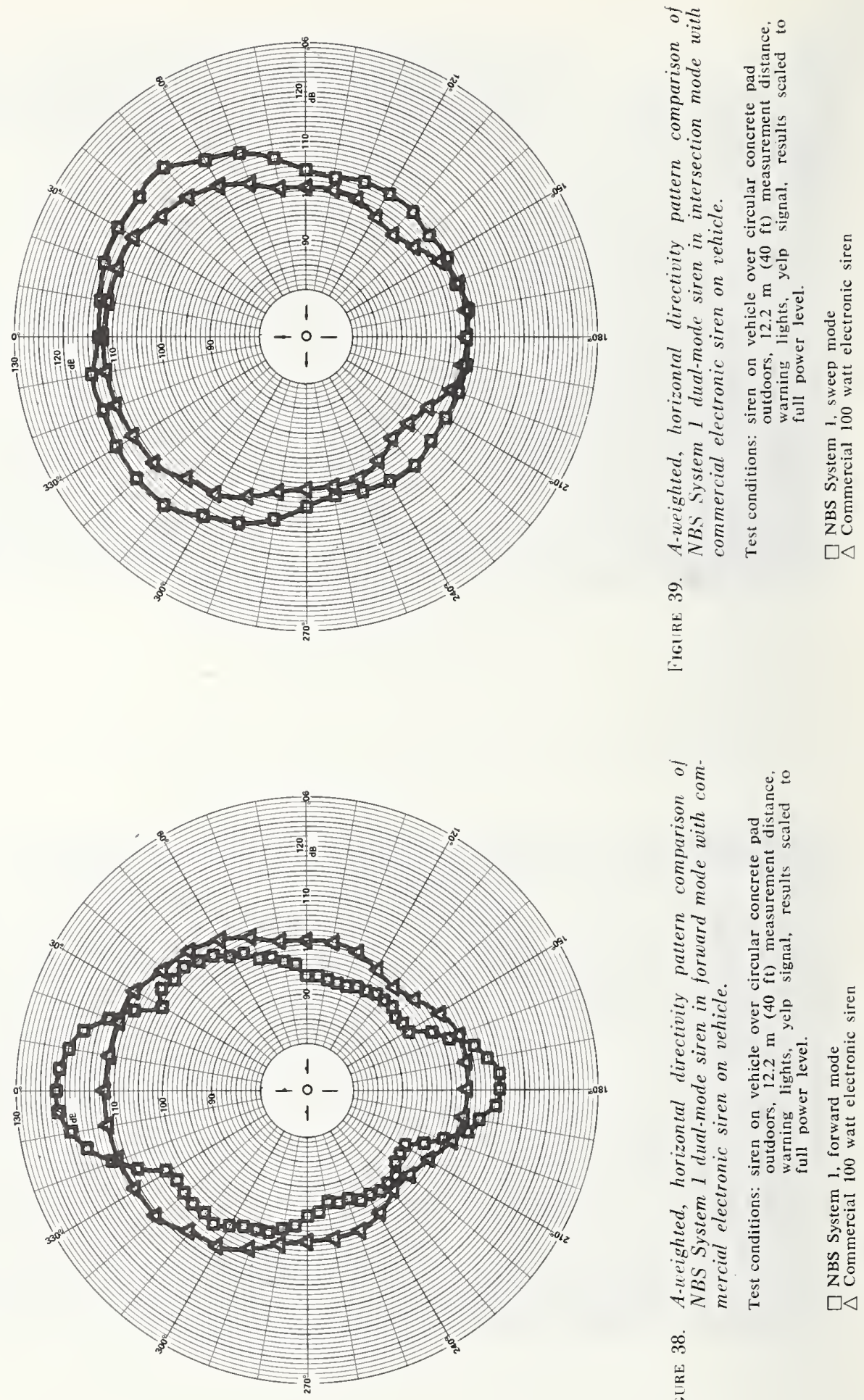

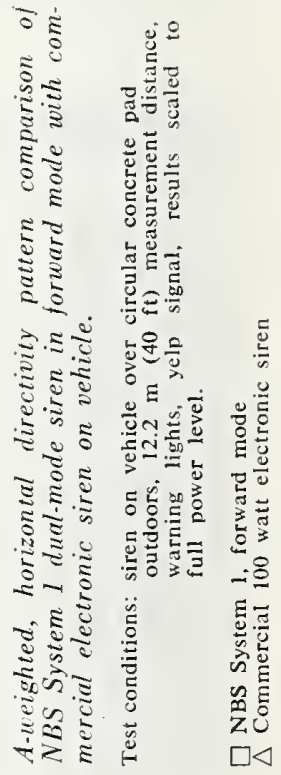

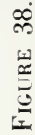


with a $7 \mathrm{~dB}$ advantage over the conventional electronic siren at $\pm 50^{\circ}$, the NBS array should be detectable at over twice the distance at which its conventional counterpart can be detected. In addition, the time variability introduced by the sweeping beam of sound may also increase the detection distance.

A second, somewhat simpler, system was also constructed and tested. While this system (NBS System 2) used the same siren control module and the same four-loudspeaker array as did System 1, it used only two (instead of four I 100-watt power amplifiers and a far simpler electronic filter network for increasing the forward beamwidth. System 2 performed as well in the forward mode of operation as did System 1. Figure 40 shows the average A-weighted sound pressure level comparison between System 2 in the intersection mode and the con. ventional electronic siren. As indicated in figure 40, System 2 also outperformed the conventional electronic siren by $7 \mathrm{~dB}$ at $\pm 50^{\circ}$ off axis.

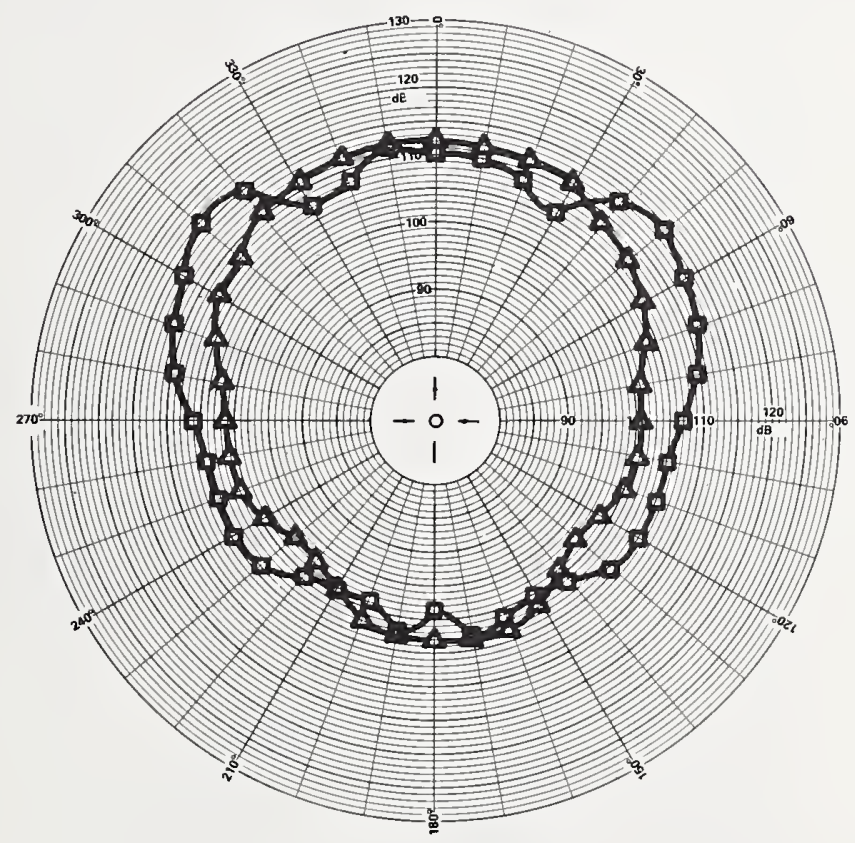

Figure 40. A-weighted, horizontal directivity pattern comparison of NBS System 2 dual-mode siren in intersection mode with commercial electronic siren on vehicle.

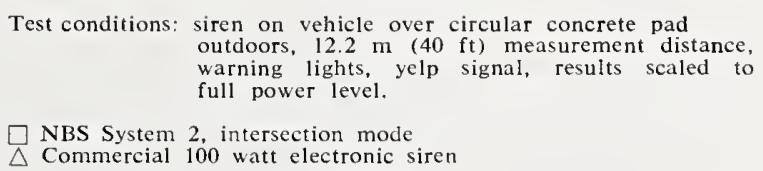

Table 1 gives a comparison of the component parts and capabilities of the NBS dual. mode siren and a conventional electronic siren.

From measurements of the NBS dual-mode siren in an anechoic room it was found that the output in the forward direction increased by $2 \mathrm{~dB}$ when the larger folded horns (figure 16) were installed on the 100.watt transducers instead of the compact horns in figure 37. 


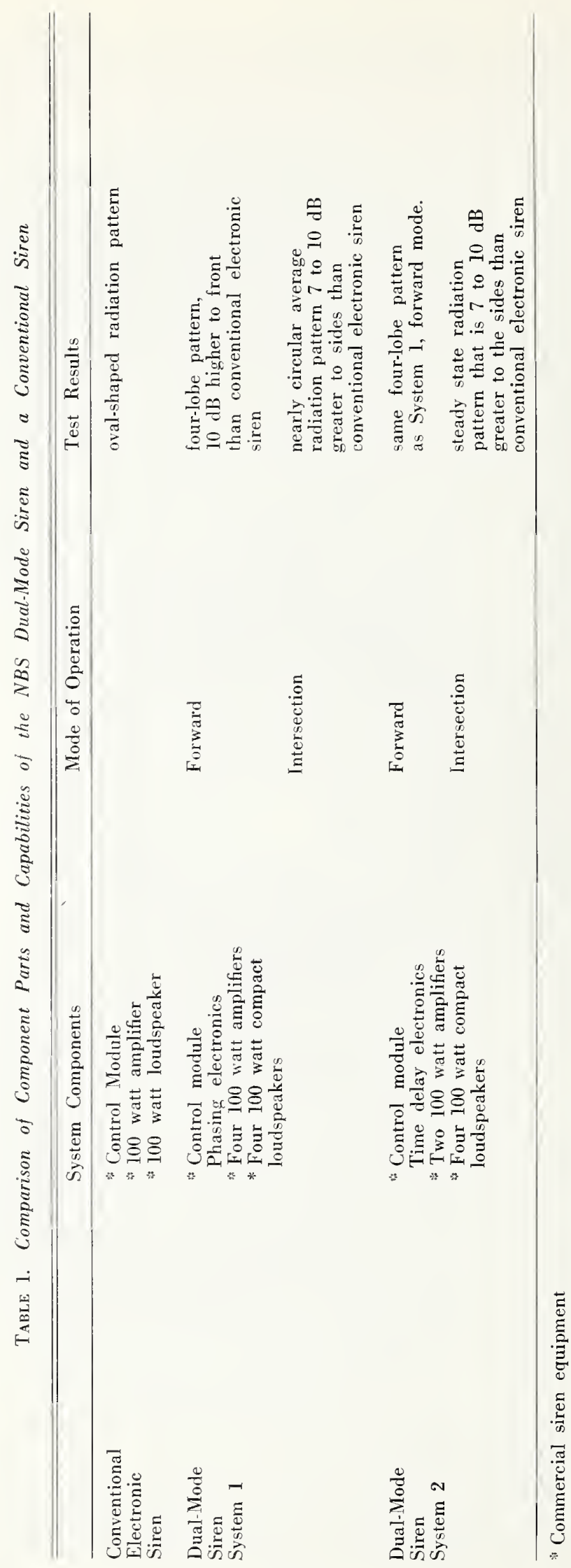


The directivity patterns of the siren array depend mostly on the spacing between and the orientation of the siren loudspeakers and on the time-delays or phasing of the electrical signals. Because the sound pressure levels produced by the array vary linearly with the input signal, the siren systems would produce the same pattern shapes at lower sound pressure levels if lower wattage power amplifiers were used.

The scaled-to-full-power A-weighted sound pressure levels inside the test vehicle at the driver's position were estimated to be about $105 \mathrm{~dB}$ based on sound level meter readings taken inside the vehicle during the low power tests of the NBS siren with the windows and doors shut. Current occupational noise exposure regulations [9] promulgated by the Occupational Safety and Health Administration (OSHA) would permit exposure to A-weighted sound levels of $105 \mathrm{~dB}$ for no longer than one hour per day.

Systems $\mathrm{I}$ and 2 were not tested for use as public address systems, but from theoretical considerations they should work well when the control switch is set to the forward mode. Human speech may not be transmitted intelligibly in the intersection modes of operation because of the time shifts or phase changes in the signal.

The average current drain of System 1 on a 13.5 volt direct current supply was 45 amperes. System 2 drew an average of 37 amperes. The commercial high-power electronic siren used 11.5 amperes.

\section{REFERENCES}

[1] Clark, M. A., An acoustic lens as a directional microphone, J. Acous. Soc. An. 25. 1152-1153 (1953).

[2] Jasik, H. I., Antenna Engineering Handbook, Chapter 5 (McGraw-Hill. New York. 1961).

[3] Jasik, H. I., op. cit, Chapter 12.

[4] Kraus, J. D., Antennas, Chapters 4 and 11 (NcGraw-Hill, New York, 1950).

[5] Kraus. J. D., op. cit., Chapter 12.

[6] Olson, H. F., Gradient microphones, J. Acous. Soc. An. 17, 192-198 (1946).

[7] Olson. H. F., Cradlient loudspeakers, J. Audio Eng. Soc. 21, 76-93 (1973).

[8] O'Neil, H. T., Theory of focusing radiators, J. Acous. Soc. Am. 21, 516-526 (1949)

[9] 36 Federal Register 10518 (29 May 1971).

\section{GLOSSARY}

Anechoic room-A room whose boundaries absorb the sound incident thereon, thereby affording essentially free-field conditions.

A-weighted sound level-A quantity, in decibels, read from a standard sound-level meter (fulfilling the requirements of American National Standard S1.4-1971) that is switched to the weighting network labeled "A." The A-weighting network discriminates against the lower frequencies according to a relationship approximating the auditory sensitivity of the human ear at moderate sound levels.

Band-pass filter-A filter that has a single transmission band extending from a lower cutoff frequency greater than zero to a finite upper cutoff frequency.

Band-reject filter-A filter that has a large insertion loss for one frequency band, neither of the cutoff frequencies being zero or infinite. 


\section{GLOSSARY-Continued}

Beam of sound-Focused or collimated sound waves from a single source or multiple sources resulting in a more intense sound wave than that which would be produced by a single less-directional source at the same distance.

Broadside array-A sound-projecting system in the form of a linear array of sources whose respective inputs are identically phased to achieve a maximum pressure or main lobe on a line perpendicular to the array. Lesser pressure maxima or side lobes may occur symmetrically about the main lobe.

Decibel-A unit of level equal to 10 times the logarithm to the base 10 of a quantity proportional to power.

Electronic siren-A warning device incorporating an electronic signal generator, an amplifier, and a loudspeaker.

Endfire array-A sound-projecting system in the form of a linear array of sources whose respective inputs are individually controlled so as to achieve a maximum pressure or main lobe in a direction along the array. Lesser pressure maxima or side lobes may occur symmetrically about the main lobe. The inputs are controlled by introducing a linear position-dependent time delay equal to the time delay arising from sound travel time differences along the array.

Free sound field (free-field) - A sound field in a homogeneous, isotropic infinite medium.

Frequency-The number of oscillations per second of a sound wave; now expressed in hertz $(\mathrm{Hz})$, formerly in cycles per second (cps).

High-pass filter-A filter having a single transmission band extending from some critical or cutoff frequency, not zero, up to infinite frequency.

Level-In acoustics, 10 times the logarithm to the base 10 of the ratio of a power-like quantity to a reference quantity of the same kind.

Low-pass filter-A filter having a single transmission band extending from zero frequency up to some critical or cutoff frequency, not infinite.

Main lobe-See broadside array and endfire array definitions.

Monopole or point source-A sound source which is small in terms of a wavelength and which generates under free-field conditions a sound pressure which is uniform in all directions and which varies inversely with distance from the source.

Phased array-A set of sources which are phased relative to each other to constructively interfere in a desired direction, thereby increasing the sound pressure level in that particular direction.

Root-mean-square (rms) - The value of a quantity that is obtained by squaring the value at each instant of time, obtaining the average of the squared value over the time interval of interest, and taking the square root of this average.

Side lobe-See broadside array and endfire array definitions. 


\section{GLOSSARY-Continued}

Siren-A device to produce warning signals used, for example, by police vehicles, fire vehicles and ambulances.

Sound pressure-The sound pressure at a point is the total instantaneous pressure at that point in the pressure of a sound wave minus the static ambient atmospheric pressure at that point.

Sound pressure level-The sound pressure level $\left(L_{\mathrm{p}}\right)$, in decibels, is defined by

$$
L_{p}=10 \log _{10}\left(p^{2} / p_{n}^{2}\right),
$$

Where $p$ is the sound pressure and $p_{0}$ is the reference sound pressure. The standard reference pressure in air is 20 micropascals $(\mu \mathrm{Pa})$.

Wail-Sound from a siren whose frequency is modulated at a rate of about 10 cycles $/ \mathrm{min}$ ute.

Yelp-Sound from a siren whose frequency is modulated at a rate of about 130 cycles $/ \mathrm{min}$. ute.

\section{APPENDIX A-DESCRIPTION OF NBS SYSTEM 1 DUAL-MODE DIRECTIONAL SIREN}

Figure A-1 shows a detailed block diagram of the swept-beam siren system. The squarewave output of the control module is connected through four independent delay circuits to the four power amplifiers which drive the system's four speakers. In the forward mode of operation the four delay circuits are programmed for the same, fixed delay. Thus, the input signals at the amplifiers are all delayed by the same amount and the outputs are in phase.

The sweep mode of operation is selected by means of a toggle switch on the siren control module (see fig. A-1). This enables the independent programming of the four delay cir. cuits. Each delay circuit is programmed to incrementally change the phase of the signal at its respective speaker. As the delay circuits are cycled through their program, the direction of the beam of sound changes in small steps (approximately $1.4^{\circ} / \mathrm{step}$ ) to sweep the acoustic beam from side to side with respect to the front of the speaker array.

The delay element of each analog delay circut is a 512 stage Bucket-Brigade Device (BBD). This device samples the analog signal at a rate determined by a two-phase clock applied to the device. The delay is effected by shifting the sampled level down through the 512 stages of the device. The delay time is thus dependent on the frequency at which the circuit is clocked.

Figure A-1 shows the components of the clock generator. The output signal from a crystal-controlled one megahertz clock is divided by 1000 to produce a one kilohertz reference frequency for the phase-locked loop (PLL). A four-digit programmable divider on the PLL output multiplies the reference frequency by a 4 -digit constant supplied from a Read Only Memory (ROM). The ROM is addressed by an 8-bit binary counter. This counter is held in a reset condition whenever the siren forward mode of operation is selected. When 
the sweep mode is selected, the counter is actuated and sequentially addresses the 256 loca. tions in the ROM in which the desired constants have been programmed. The siren beam is swept through one complete cycle (center-left-center-right-center) for every 256 counts of the counter. The cycle time can be adjusted as desired; for demonstration purposes, a cycle time of about four seconds has been used.

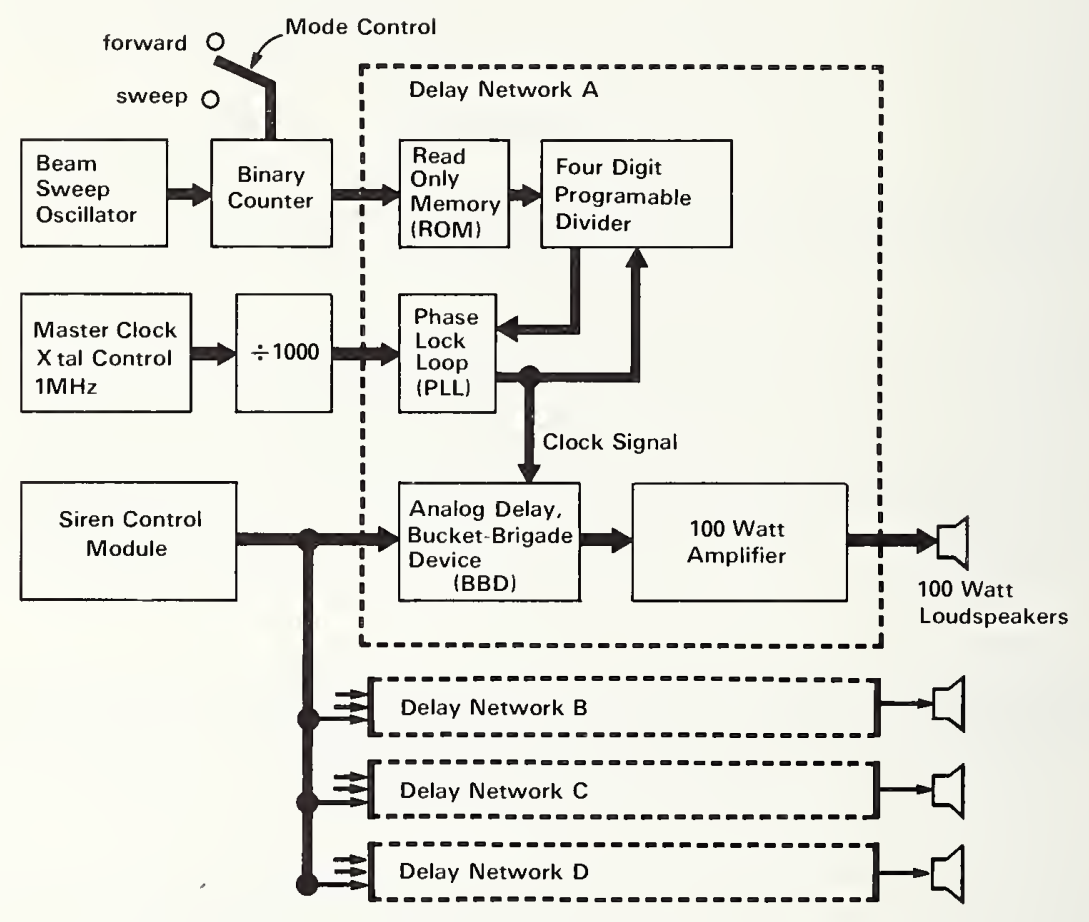

Figure A-1. Block diagram of swept-beam dual-mode siren (System 1).

\section{APPENDIX B-REASONS FOR CHOOSING A BROADSIDE ARRAY AND DESIGN OF NBS SYSTEM 2 DUAL-MODE DIRECTIONAL SIREN}

In designing an acoustic array for an emergency vehicle siren, it is desired to have a narrow beam projected in one direction (forward) and, alternatively, to have beams projected diagonally to the front-sides. If a broadside array is chosen to project one beam pattern, it follows that an endfire array (or some other means of projecting a beam along the line of the array) must be used for projecting the alternative beam pattern. A study of the monopole (point source) approximation for evenly-spaced radiators reveals that, in general, the broadside patterns have rather thin pencil-like main lobes perpendicular to the array (fig. B-1) while the endfire array gives a broader main lobe in one direction along the line of the array (fig. B-2). So, if an intense back lobe is not a major concern, then a broadside array (for a forward-directed beam) can be used to reduce radiation to the side over a broad frequency range. So far the assumption has been made that the sources will be kept on one line. Greater flexibility is possible by placing the sources in a two dimensional array in a 


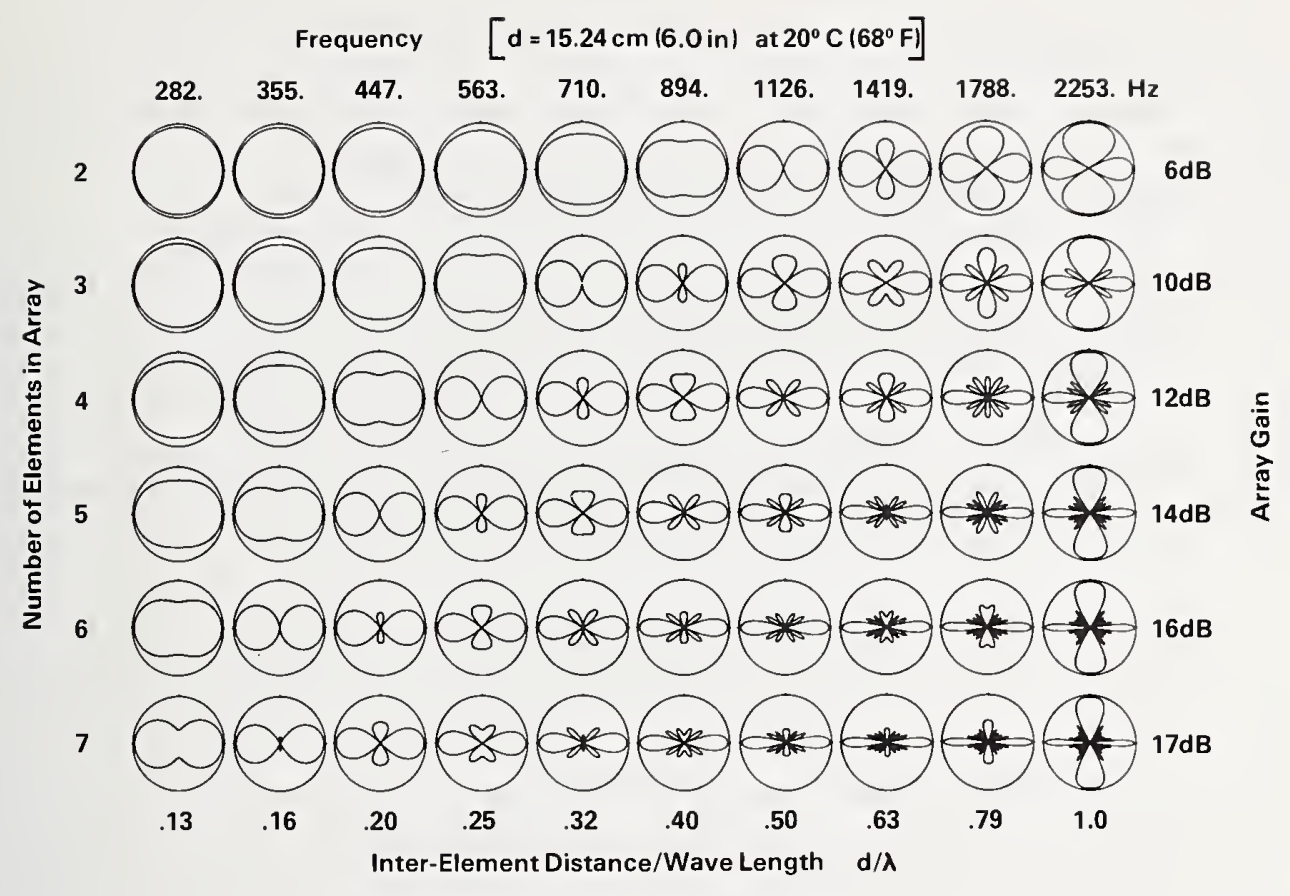

FIGI RE B-1. Theoretical directivity patterns for lineur broadside point source arrays $(25$ db range).

Frequency $\quad\left[\mathrm{d}=9.14 \mathrm{~cm}(3.6 \mathrm{in})\right.$ at $\left.20^{\circ} \mathrm{C}\left(68^{\circ} \mathrm{F}\right)\right]$

373. 469. 591. 745. 939. 1183. 1490 . 1877. 2365. 2980. 3755. Hz

2

and and

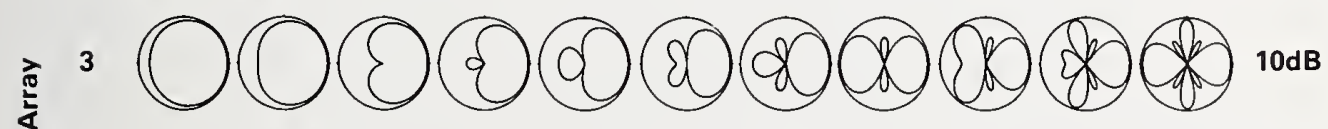
5

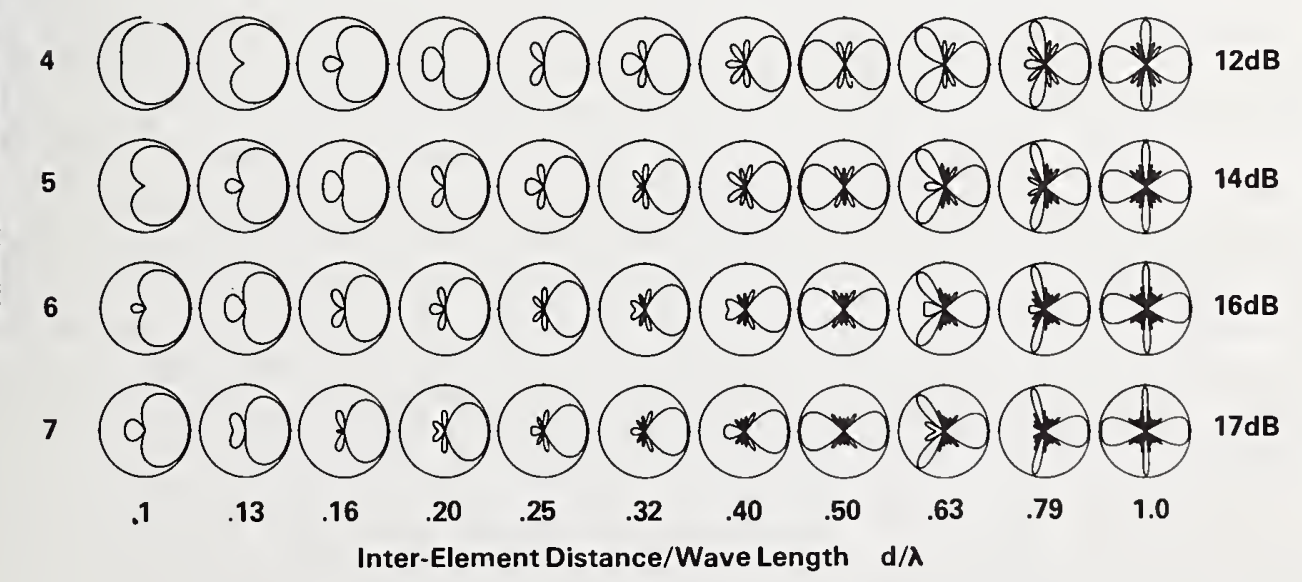

Figure B-2. Theoretical directivity patterns for linear endfire point source arrays (25 dB range). 
plane parallel to the ground. Such a possibility was not thoroughly investigated, in part for the reason that the additional dimension greatly increases the array configuration possibil. ities, making a thorough investigation a much more time-consuming task. Furthermore, it should be kept in mind that the design goal was to create an array that projects contrasting beam patterns, in terms of beam width. For a fixed number of sources, the general influence of placing spacings other than on one line is to reduce this potential contrast. Thus, the broadside array was chosen for projecting the forward beam.

The beamwidth projected by a broadside array depends on how many sources are used. As the number of sources is increased, the side-radiation attenuation not only increases but does so over a broader frequency range. The fundamental frequency range for the siren signals used for this study is $500 \mathrm{~Hz}$ to $1500 \mathrm{~Hz}$. The plots in figure B-1 show that at least four sources are needed to cover such a frequency range with good side reduction. For four-element arrays a desirable $d / \lambda=d f / c$ range is 0.22 to 0.69 (where $d$ is the element spacing, $\lambda$ is wavelength, $f$ is frequency and $c$ is the speed of sound). Solving for $d$ with the corresponding $\lambda$ for 500 and $1500 \mathrm{~Hz}$ yields $d=15 \mathrm{~cm}$ (6.0 in). This is a convenient spacing since it is typically the minimum possible with sirens placed side by side.

A rough analogy can be made between the amplitude attenuation effects of an array for any given direction from the array and the attenuation effects produced by electrical fllters. For the broadside array, when measuring the resultant amplitude to the side, the acoustical cancellation creates, in effect, a band reject filter. A band reject filter is characterized by a frequency band in which the filter attains some degree of amplitude attenuation at all frequencies from the lower bound of the band to the upper bound of the band. In this case, the lower bound of the side radiation attenuation is defined by the return to a monopole (omnidirectional) radiation pattern. The upper bound is defined by the emergence of a side lobe which reaches the full potential strength of the array when $d / \lambda=1.0$. This analogy is of no importance to the broadside array since a desirable radiation pattern is attained in the frequency band of interest with one array configuration. However, the analogy will be of use in designing a system for creating an alternate radiation pattern.

Next consider the possibilities for creating a sideways-directed radiation lobe pattern or, if possible, an omnidirectional pattern, for use at intersections. A strict endfire array requires time-delay electronics and "fires" primarily in one direction. Variations of the endfire array which give symmetrical directivity patterns include symmetrical and asymmetrical transducer signal phasing patterns.

For four (or any other even number of) transducers, asymmetrical phasing can be obtained by an alternating plus to minus phasing to successive loudspeaker elements. Any phasing other than plus and minus $180^{\circ}$ to the alternate elements will not give a symmetrical overall directivity pattern about the forward axis. When measuring the resultant amplitude to the side, the acoustical addition creates, in effect, a band pass filter. The effective band center frequency comes about when $d / \lambda=0.5$ (see fig. B-3). For the chosen spacing, $d=15$ $\mathrm{cm}(6.0 \mathrm{in})$ and the center of the band is about $1000 \mathrm{~Hz}$. It is no coincidence that $1000 \mathrm{~Hz}$ also corresponds to the center of the reject band for the unphased broadside array. Having all the elements phased the same at a spacing of $15 \mathrm{~cm}$ means that a waveform with alternately phased peaks every $15 \mathrm{~cm}(\lambda=30 \mathrm{~cm})$ will tend to be cancelled out by the contribution from adjacent elements. Alternately phased elements, on the other hand, are exactly what are needed to reinforce such a waveform along the length of the array. For frequencies away from $\mathrm{d} / \lambda=0.5$ the reinforcement is slowly lost. The effective $3 \mathrm{~dB}$ down points relative to $1000 \mathrm{~Hz}$ for radiation to the side are at about $800 \mathrm{~Hz}$ and $1.3 \mathrm{kHz}$.

At $45^{\circ}$, when using alternate phasing, the amplitude peaks around $1400 \mathrm{~Hz}$ had $3 \mathrm{~dB}$ down points at about $1120 \mathrm{~Hz}$ and $1800 \mathrm{~Hz}$. Thus the alternate phasing technique still represents a way of spreading sound by angles less than $90^{\circ}$ from the front for frequencies above $1000 \mathrm{~Hz}$. The theory for creating an amplitude peak at $45^{\circ}$ or any other angle is similar to 


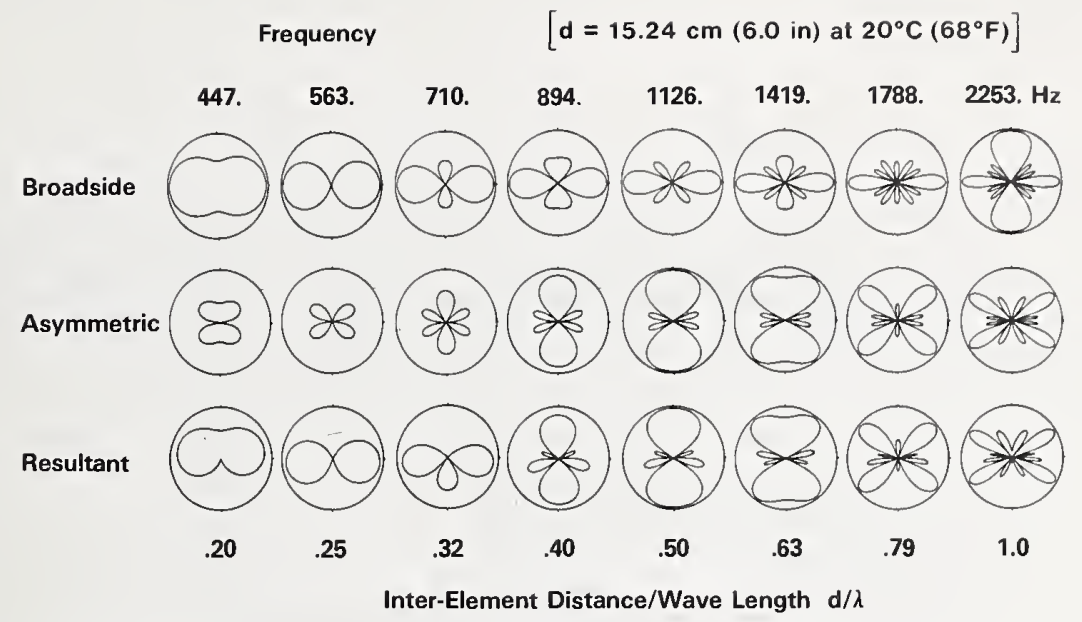

Figlike B-3. Theoretical directivity patterns for System 2 array (2.5 db range).

that at $90^{\circ}$ except that the effective spacing, $d$, along any angle is less than the full spacing which exists only at $90^{\circ}$; thus frequency is, in a sense, scaled and the effective $d / \lambda=0.5$ frequency occurs higher than for $90^{\circ}$.

The directivity pattern for the alternate phasing asymmetrical technique for frequencies below $800 \mathrm{~Hz}$ is poor in any direction (see fig. $\mathrm{B}-3$ ). The radiated power is similar to that obtained from a dipole contribution at best, and no matter what the actual radiation pattern. the sound pressure level at any given angle will fall off drastically at low frequencies. The only possibility for saving on the amount of radiated power is by returning to the use of a monopole-type source, or in other words an unphased broadside array, at low frequencies.

Thus, it appeared that a combination of an alternate phased asymmetrical endfire array used at mid and high frequencies, and an unphased broadside (monopole type) source at low frequencies, would be a desirable compromise for the creation of a somewhat omnidirectional radiation pattern which emphasizes the side radiation. In the extreme low frequency limit the radiation will be in all directions. However, since the purpose of the use of an unphased broadside array was to obtain amplitude reduction to the side, in the actual low frequency limit used, the main contribution will be in the forward direction. Since this was the only direction left without radiated power by the alternately phased array, the summation over frequency of the power from the two types of arrays should be somewhat omnidirectional. The degree of omnidirectionality attained is a function of the horn frequency response as well as the frequency-versus-time dependence of the siren signal.

The desired phasing network should develop an out-of-phase signal for frequencies greater than $800 \mathrm{~Hz}$ and an in-phase signal for frequencies less than $800 \mathrm{~Hz}$. The difference in phase versus frequency means that at least 2 power amplifiers are required with one of them receiving a phased signal from an active network. The network used to attain this consisted of summed notch and peak filters and is shown in figure B-4. A peak filter in the 850 $\mathrm{Hz}$ range is left uninverted and its output is summed. Also uninverted and summed with it are the outputs of two notch filters in the 500 to $700 \mathrm{~Hz}$ range. These introduce additional phase shift in the desired direction below $800 \mathrm{~Hz}$. Finally, the outputs of two peak filters in the 500 to $700 \mathrm{~Hz}$ range are summed with inversion. The total sum is approximately an all-pass network with the required phase shifted resultant. The measured filter phase response is shown in figure B-5. The resultant theoretical directivity patterns for a pure tone input us- 
ing the measured filter phase response are shown in figure B-3. The resultant shows a shift around $800 \mathrm{~Hz}$ from a preference for the broadside directivity pattern to a preference for the asymmetrical patterns.

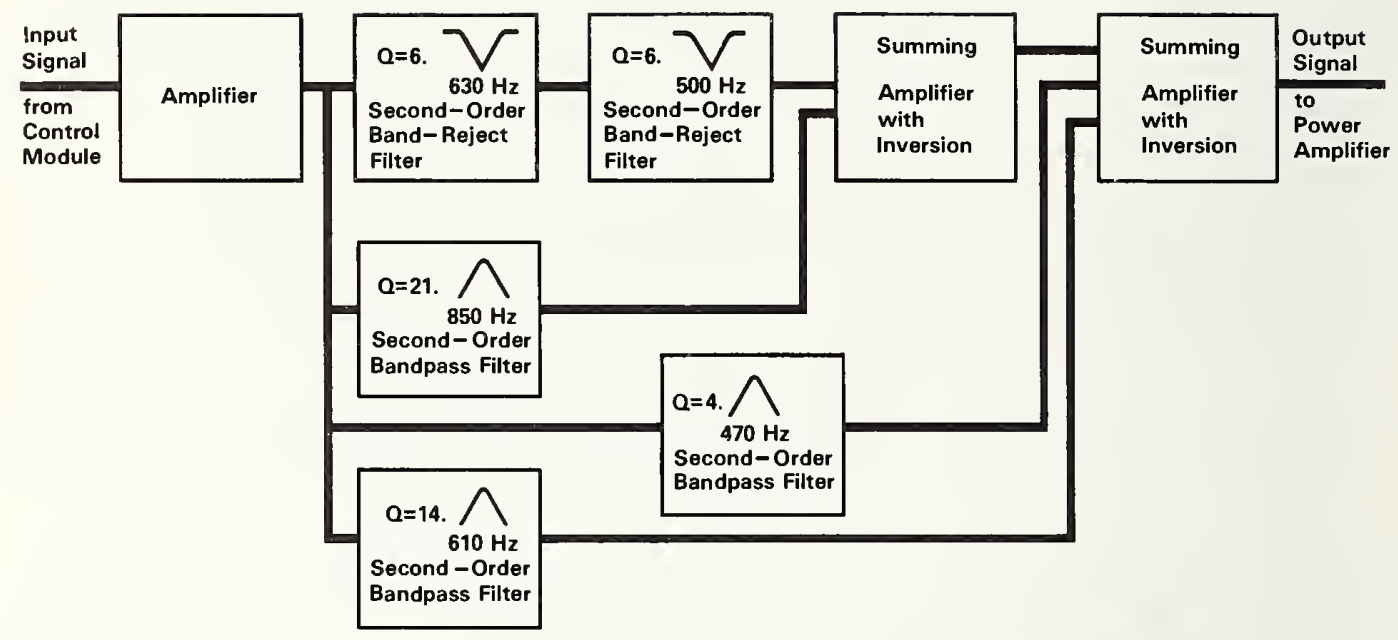

Figure B-4. Block diagram of phasing network, jor NBS asymmetrically phased dual-mode siren (System 2).

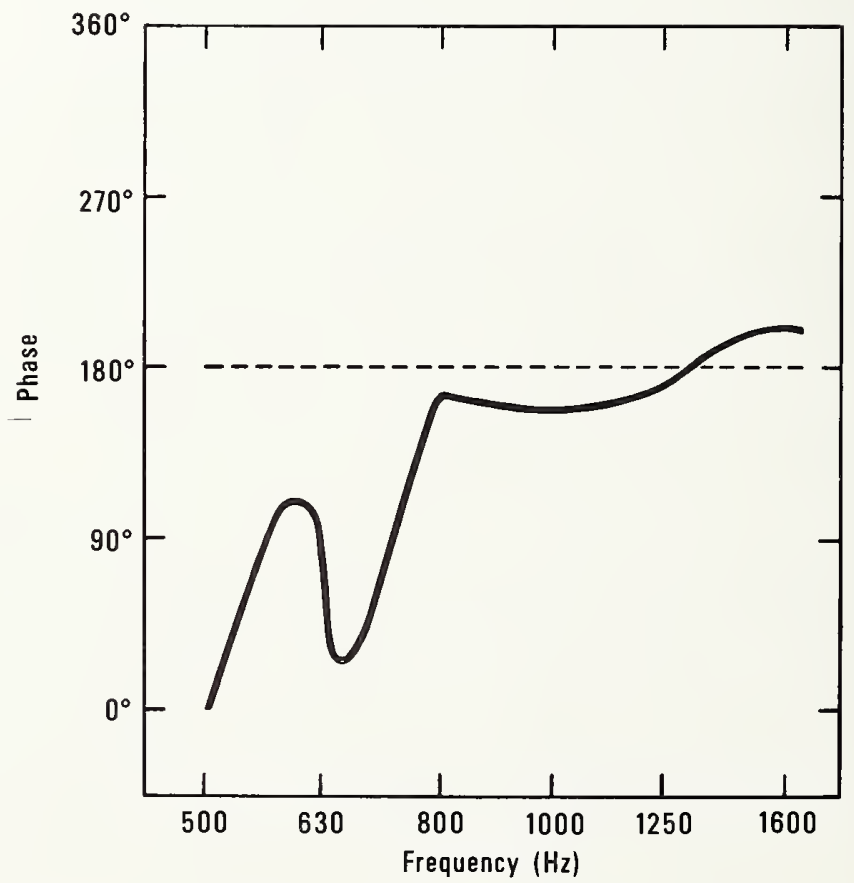

Figure B-5. Measured phase of filter for asymmetric array. 
A number of factors could cause differences between the measurcd radiation patterns and those predicted from the array design as considered so far. One factor is that the actual siren signal used is a square wave rather than a simple sine wave. Another is that the sources are not point sources. Some consequences of these factors are considered next.

It can be noted that some additional forward strength is gained with the return to a broadside array at low frequencies with Class D amplifiers which are used with these siren systems. The harmonics of the output of a Class D amplifier are always phased to give a square wave. The first harmonic of $500 \mathrm{~Hz}$ is $1500 \mathrm{~Hz}$ and this harmonic will have broadside phasing as the fundamental reaches $500 \mathrm{~Hz}$, if the array elements are connected so that the fundamental frequency is also broadside phased. The response of the horns reaches a peak around $1600 \mathrm{~Hz}$. So, despite the downward weighting of the harmonics of a square wave, the first harmonic of the low frequencies will be beamed forward with strength similar to the fundamental. These factors help to prevent a dip in the sound pressure level on axis.

The monopole (point source) approximation is best for $\theta=0^{\circ}$. At this aspect angle, the horn mouths used in a practical siren configuration appear visually as flat discs with no spatial spreading in the direction of intercst. To the side the monopole approximation is at its worst since the flat discs formed by the horn mouths are seen end on. Since the horn mouths used were 90 percent as wide or the same width as the horn spacing, some phase cancellation occurs between the velocity distributions along the line of the alternately phased horns. To obtain an estimate for the degree of cancellation this spatial spreading of the source has at $\theta=90^{\circ}$, one can model the sirens as four uniform line radiators of length $\mathrm{d}$ placed end to end. In order to give each radiator unity strength when integrated over its length. normalize the strength by a factor of $1 / d$. Then the spatial Fourier Transform of the amplitude in any direction $\theta$ is:

$$
\begin{aligned}
& A(\theta)=\frac{1}{\mathrm{~d}} \int_{-2+1}^{2+d} e^{-j k x}\lceil H(x+2 d \sin \theta) \\
&-2 H(x+d \sin \theta)+2 H(x)-2 H(x-d \sin \theta) \\
&+2 H(x-2 d \sin \theta)\rceil d x
\end{aligned}
$$

$H(x)$ is the unit step function defined by:

$$
H(x)=\begin{array}{ll}
0 & x<0 \\
1 & x \leq 0
\end{array}
$$

When the equation is evaluated it is found that the maximum available source strength at $\theta=90^{\circ}$ from four unity strength radiators is reduced from the point source value of 4 to $8 / \pi$ or 2.55 at a value of $d / \lambda=0.5$. Since the true horn velocity distribution over its mouth, in the shape of a disc, will be closer to a point source than this approximation allows. the true reduction in amplitude should not be this great. However, the reduction was measured to be greater than this. Scattering effects, as yet unconsidered in this analysis, may be responsible for this additional reduction.

An alternative to the asymmetric system just described is a symmetrical system where the inner two sirens are phased differently from the outer two. One form of this is to consider the four sirens to be two endfire arrays back to back. This is only a reasonable first order approximation since interactions exist between the two endfire arrays. The required phasing at $1000 \mathrm{~Hz}$ is again $180^{\circ}$. but now it is desired to have a slow variation about this value at other frequencies which makes the filter synthesis process easier. The desired phasing is given by :

$$
\theta=k d=2 \pi \frac{d}{\lambda} .
$$


Plots of the directivity patterns versus $d / \lambda$ are shown in figure B-6. Below $d \lambda /=0.5$ the array elements are less than $180^{\circ}$ out of phase and no nulls occur versus angle. From $d / \lambda=0.25$ to $d / \lambda=0.4$ the radiation patterns have maxima to the sides. At $d / \lambda=0.5$ a cloverleaf is formed with maxima at $45^{\circ}$ and 135 and minima at $0^{\circ}$ and $90^{\circ}$. Above this frequency side-maxima return, as well as maxima to the front and rear. So, as with the asymmetrical system, the integrated power over frequency and versus angle is a reasonably omnidirectional pattern. Again the degree of omnidirectionality attained is a function of the horn frequency response as well as the frequency-versus-time dependence of the siren signal. The measured directivity pattern is shown in figure B-7.

\section{Frequency}

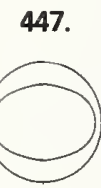

.20

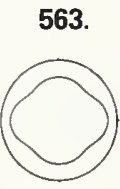

.25

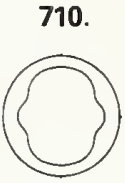

.32

$\left[\mathrm{d}=15.24 \mathrm{~cm}(6.0 \mathrm{in})\right.$ at $\left.20^{\circ} \mathrm{C}\left(68^{\circ} \mathrm{F}\right)\right]$

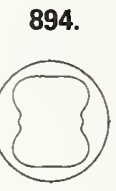

.40
1126.

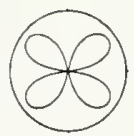

.50
1419.

1788. 2253. $\mathrm{Hz}$

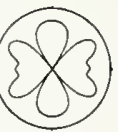

.63

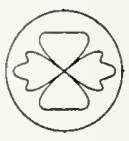

.79

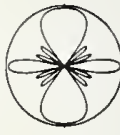

1.0

Inter-Element Distance / Wave Length $d / \lambda$

Figure B-6. Theoretical directivily patterns for symmetric array (25 dB range).

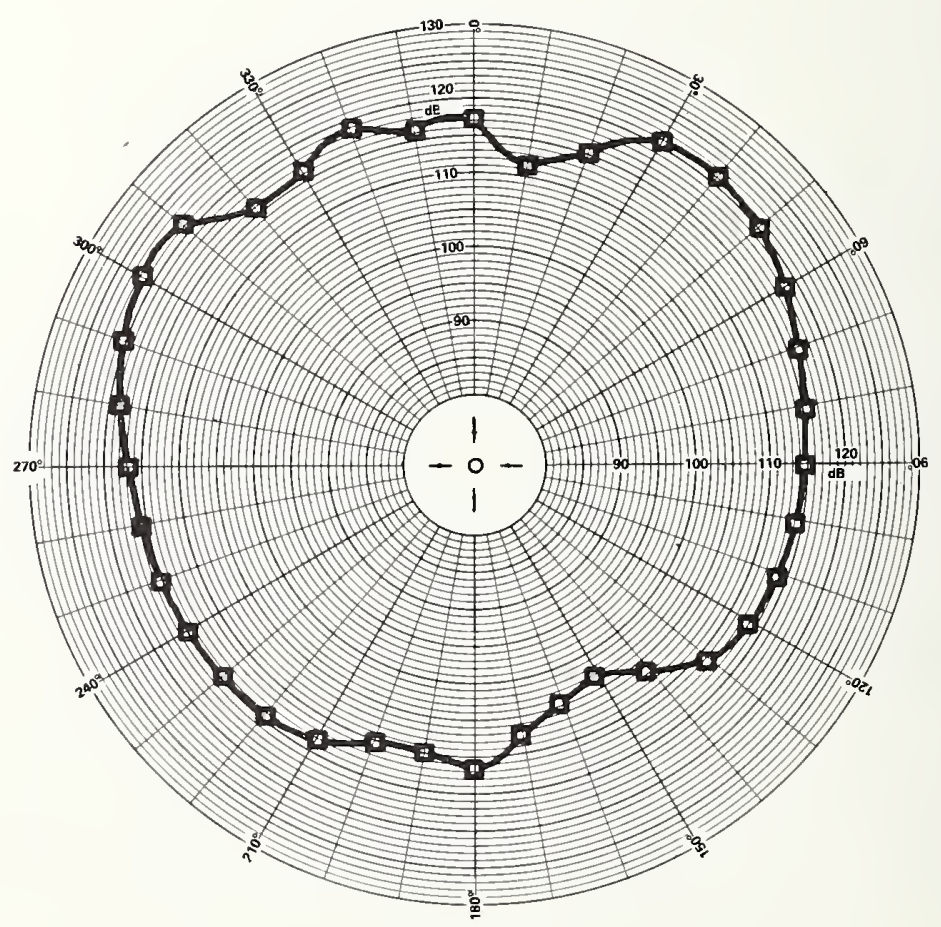

Figure B-7. A-weighted, jull power horizontal directivity pattern for symmetric phased siren array in intersection node (modified System 2).

Test conditions: free field, $3 \mathrm{~m}(9.8 \mathrm{ft})$ distance, yelp signal. 
Again, the presence of one alternately phased signal requires at least two power amplifiers. The network used to attain this, as shown in figure $\mathrm{B}-3$, consisted of the summation of an inverting $470 \mathrm{~Hz}$ low pass filter and a $1250 \mathrm{~Hz}$ peak filter.

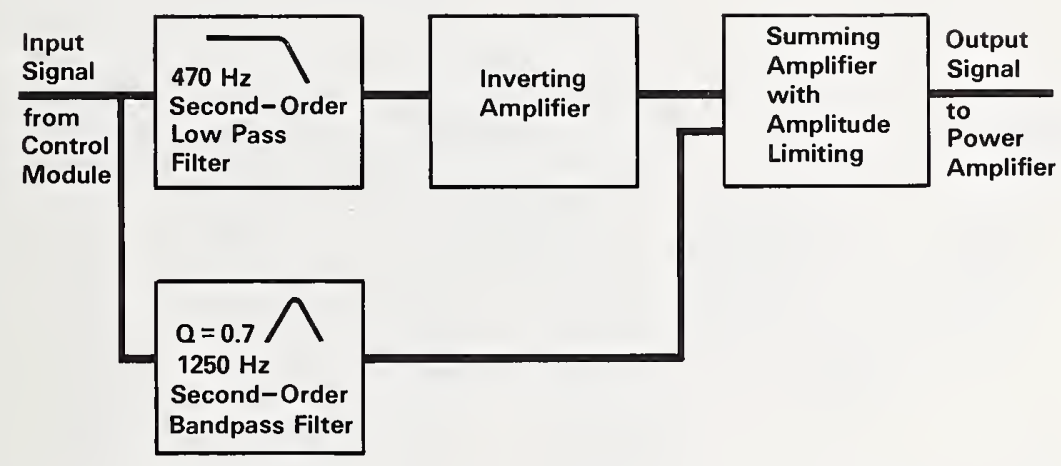

Figure B-8. Block diagram of phasing network for NBS symmetrically phased dual-mode siren (modified System 2).

\section{APPENDIX C-CIRCUIT DIAGRAMS FOR NBS SYSTEMS 1 AND 2}

Appendix C consists of four circuit diagrams depicting the electronic components used in the NBS-developed time delay or phasing electronic modules for the directional siren. The circuit diagrams do not show the remaining commercially made part of the siren such as control module, power amplifiers, and loudspeakers.

Figures $\mathrm{C}-1$ and $\mathrm{C}-2$ are the circuit diagrams for the NBS System 1, swept-beam siren. Figure C-3 is the circuit diagram for the NBS System 2, asymmetrically phased siren. Figure $\mathrm{C}-4$ is the circuit diagram for the NBS System 2 modified to produce symmetrical phasing. 


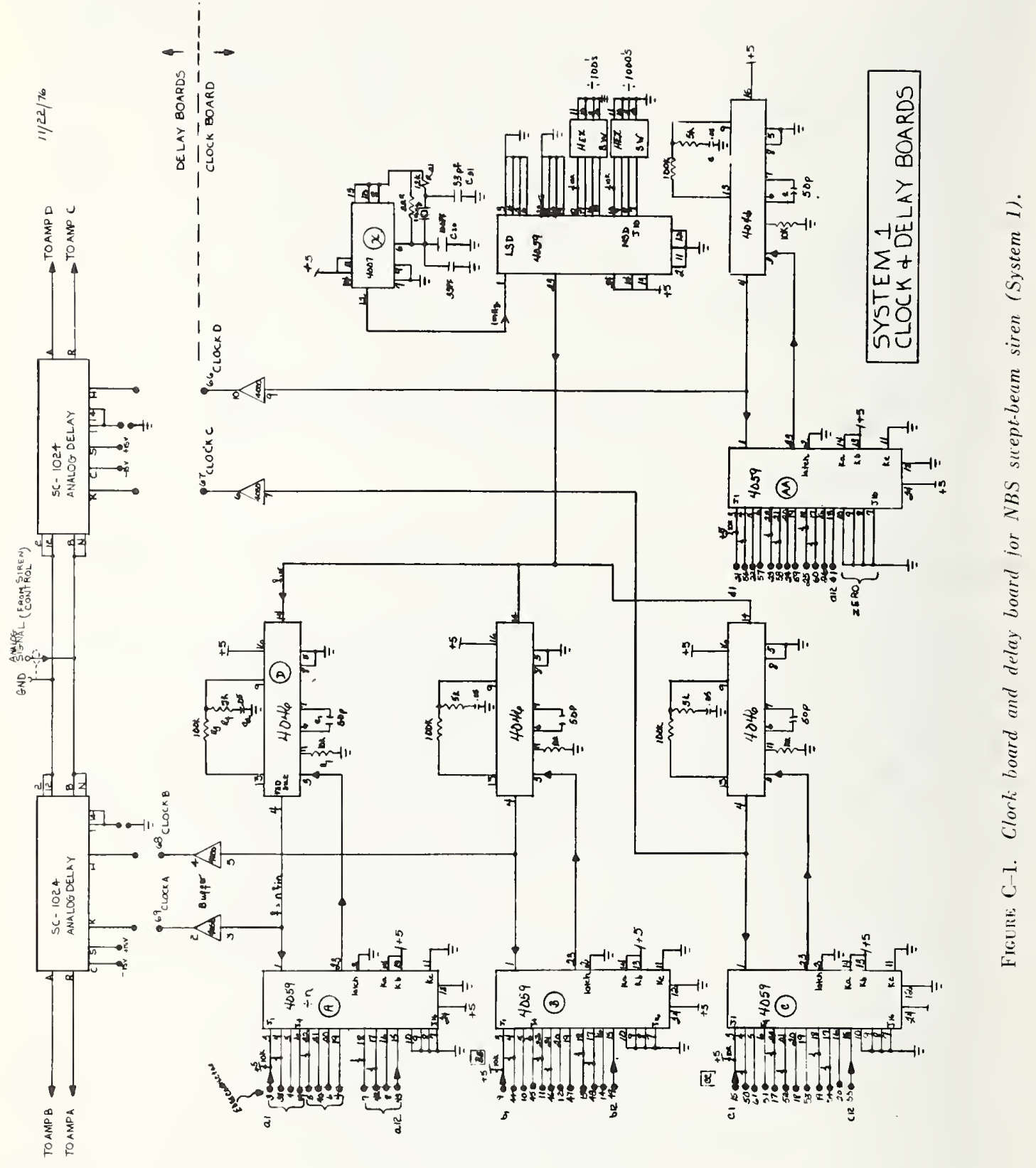



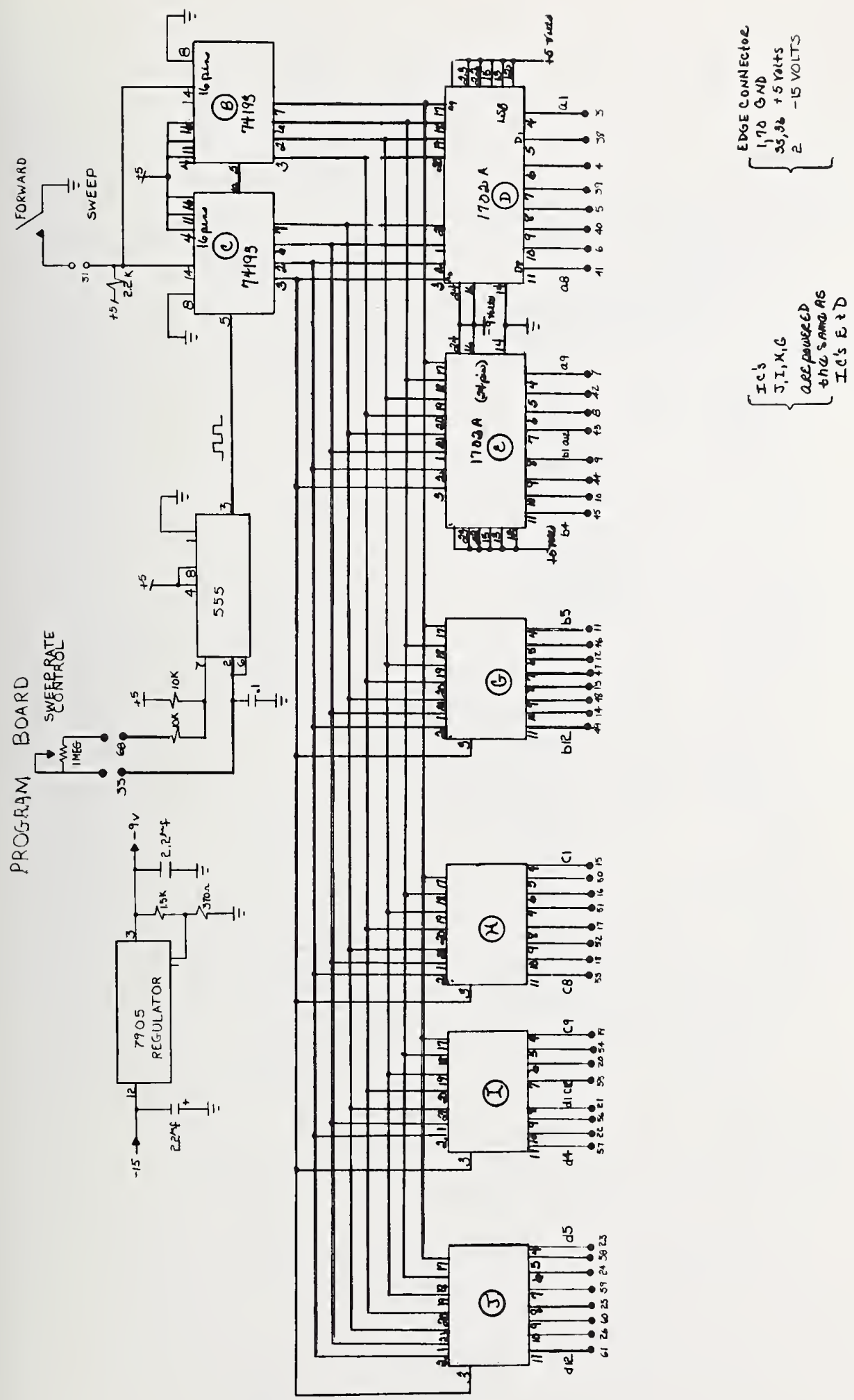

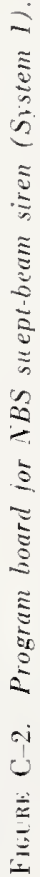



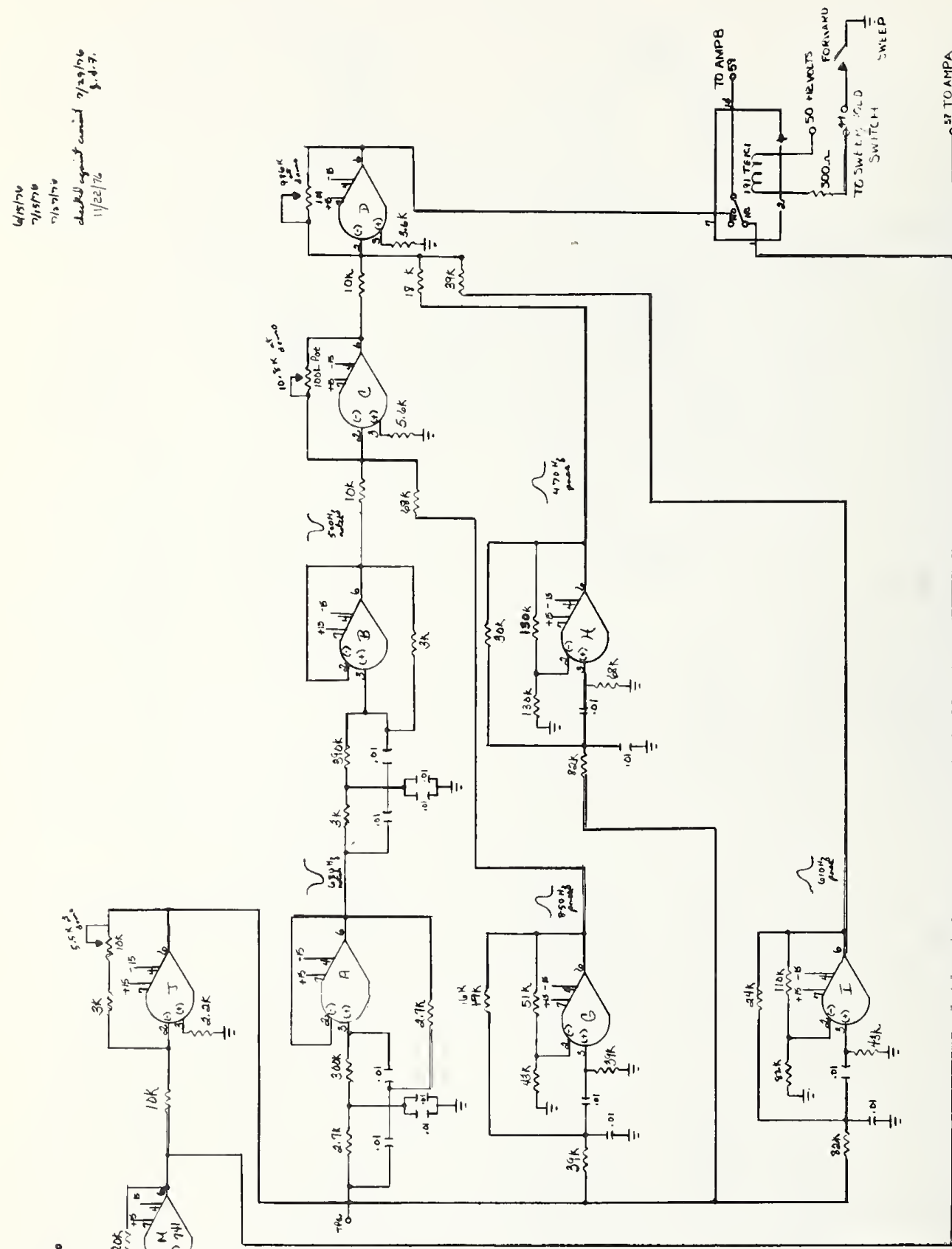

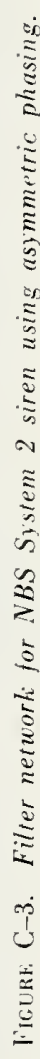

$\therefore+\frac{1}{2}$

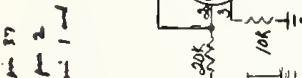

1191

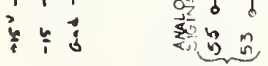

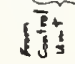




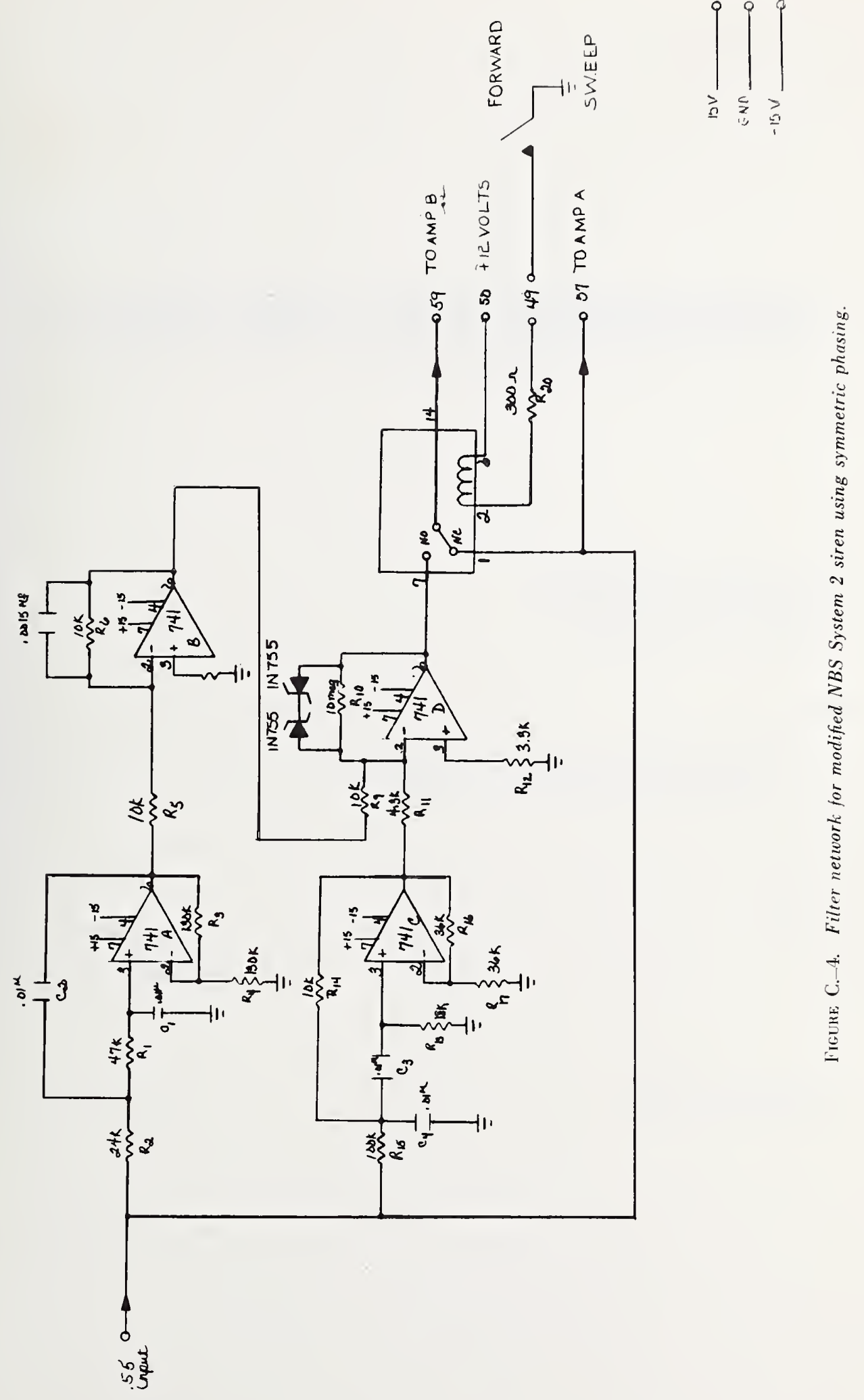




\section{ANNOUNCEMENT OF NEW PUBLICATIONS ON NATIONAL CRIME AND RELATED SUBJECTS}

Superintendent of Documents,

Government Printing Office,

Washington, D.C. 20402

Dear Sir:

Please add my name to the announcement list of new publications to be issued on the above subjects (including this NBS series):

Name

Company

Address

City State Zip Code 

U.S. DEPARTMENT OF COMMERCE

National Bureau of Standards

Washington, 0.C. 20234

OFFICIAL BUSINESS

U.S. OEPARTMENT OF COMMEACE COM-215

Penalty for Private Use. $\$ 300$

SPECIAL FOURTH-CLASS RATE BOOK 